
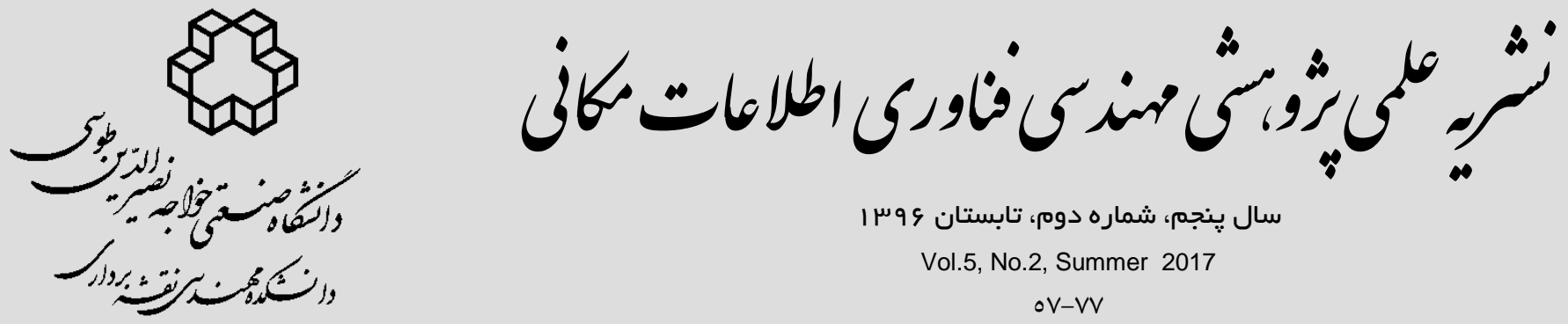

سال ينجم، شماره دوهم، تابستان و وس

Vol.5, No.2, Summer 2017

oV-VV

رديابى بازيكنان در تصاوير ويدئويى مسابقات فوتبال با تلفيق روشهاى تراف و هوش جمعى

مهر تاش منافى فرد'"، حميد عبادى '، حميد ابر يشمى مقدم"

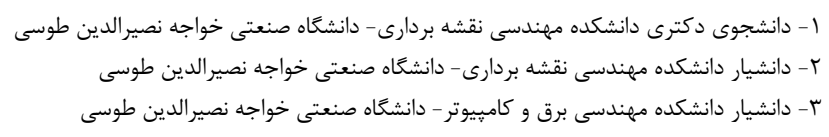

تاريخ دريافت مقاله:

جكيده

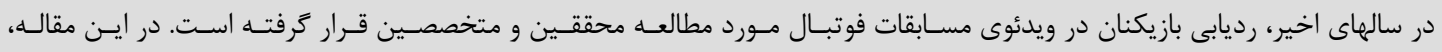

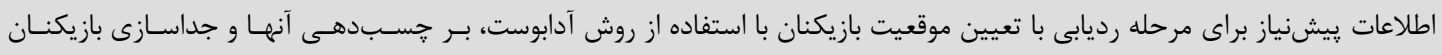

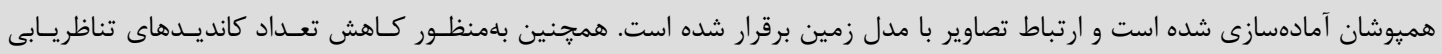

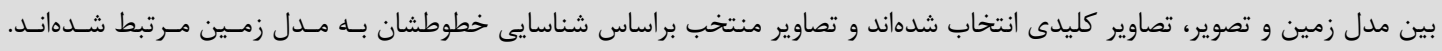

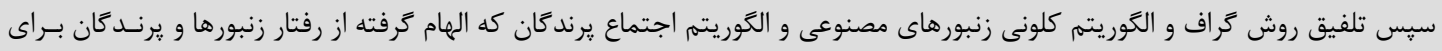

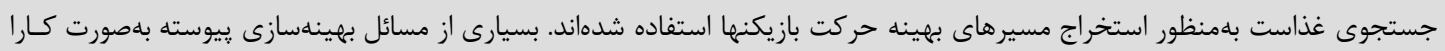

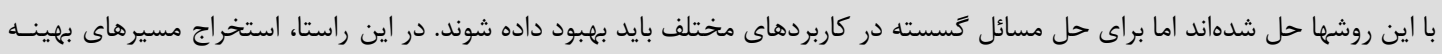

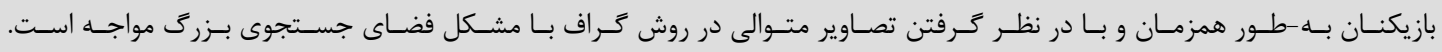

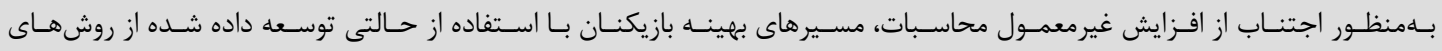

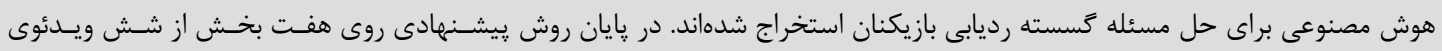

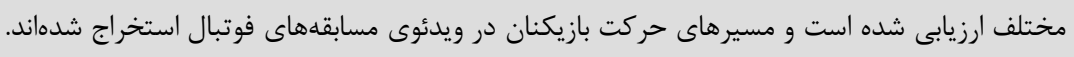

كليدوازهها: رديابى، فوتبال، يرندكان، زنبورها، كراف، مرتبطسازى، تصوير كليدى.

"نويسنده مكاتبه كننده: دانشكده مهندسى نقشه بردارى - دانشكاه صنعتى خواجه نصيرالدين طوسى - تهران - ايران تلفن : MYVV.YIA 


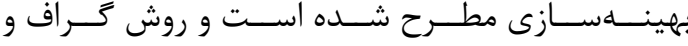

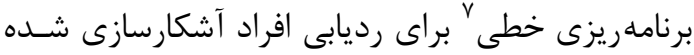
در تصاوير به كار برده شـده اسـت. روش بــراى تصـاوير اخذ شده از دوربينهاى ثابت ارزيابى شده است كه قيد ثابت بودن دوربـين در رديـابى بازيكنـان در ويــئوهاى مسابقات فوتبال صادق نيست.

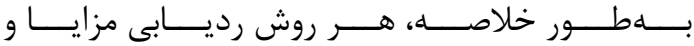

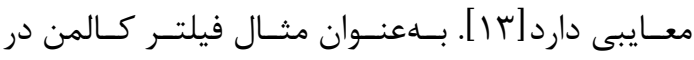

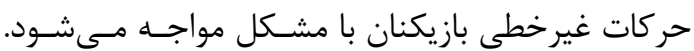
كارايى فيلتر ذراى نيـز بــه تعـداد ذرات بسـتخى دارد. اگر تعـداد ذرات زيــاد انتخــاب شـود، زمـان محاسـبـات

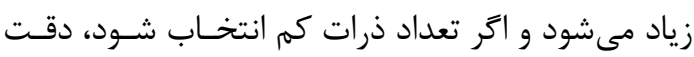
تعيين موقعيت بازيكنان كم مىشود. روش اسنيك نيـز

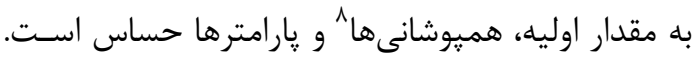

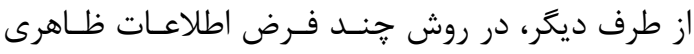
درنظر كرفته نمى شوند و حجم محاسـبات زيـاد اسـت.

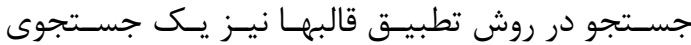
سخت ' است كه اين مشكل در روش جابجايى ميانكين حل مىشود. در روش جابجايى ميـانخين، اخـر بـازيكن داخل ينجره جستجوى اوليه نباشد، رديابى نمسىشـود.

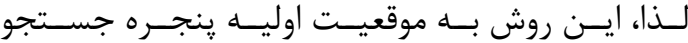

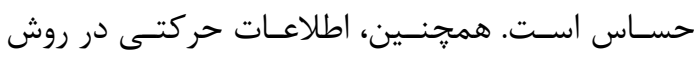

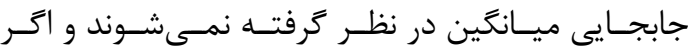

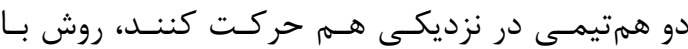
مشكل مواجه مىشود. در اين تحقيق، رديابى بازيكنان برخلاف تحقيقات قبلى مولى مودي

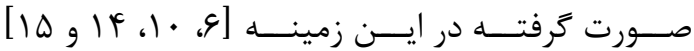

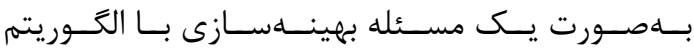

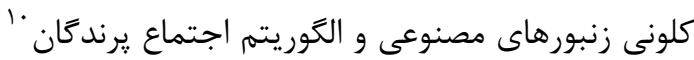
مطرح شده اسـت و بازيكنـان بـا انتخــاب محتملتــرين مسيرها در گراف باعنوان مسـيرهاى حركـت بازيكنـان

\footnotetext{
${ }^{7}$ Linear Programming

${ }^{8}$ Occlusions

${ }^{9}$ Exhaustive search

${ }^{10}$ Particle swarm optimization (PSO)
}

- - 1- مقدمه

در سالهاى اخيـر، تجزيـهـ و تحليـل ويـدئوهاى ورزشـى بـهمنظــور اسـتخراج اتوماتيـك اطلاعـات از ويــئوهاى در دسترس و ويدئوهاى مسابقات مختلـف مــورد توجــهـ

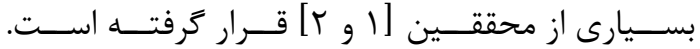

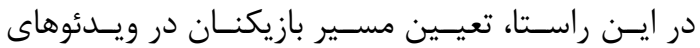
مسابقات فوتبال بهعنوان اساس بررسى استراترى بـازى

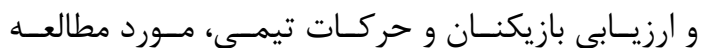
محققين [ا و r] قرار كرفته است.

در مقالات ارازيو و همكاران [1] و اسـكويى و همكـاران [r] مــرورى بــر روشهــاى مختلـف رديـابى بازيكنــان

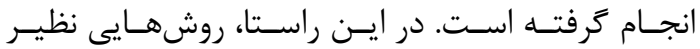

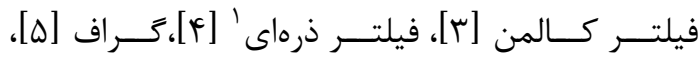

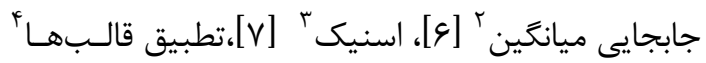

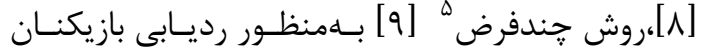

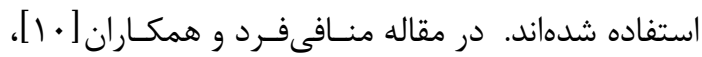
بازيكنان بعد از تعيين موقعيت و تعيين تيم هر بـازيكن با روش گراف رديابى شـدهانـد. در ايسن روش بـهـدليـل در نظر گرفتن قيـود انعطـافنايـذير در مرحلـه تعيـين مسير هر بازيكن (نظير در نظرگرفتن نزديكترين بازيكن

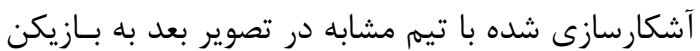

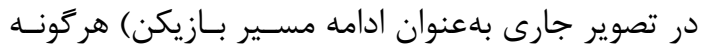
خطا در مرحله برجسبدهـى (تعيسين تـيهم) منجــر بـهـ كسسته شدن مسير حركت بازيكن شده است. در مقاله

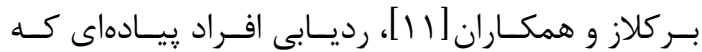
در حال قدم زدن هستتند بهصورت مسئله بهينـهسـازى

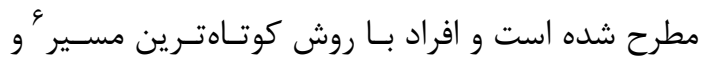

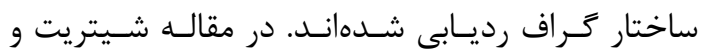

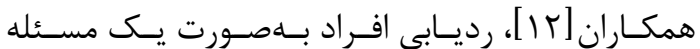

\footnotetext{
${ }^{1}$ Particle filter

${ }^{2}$ Meanshift

${ }^{3}$ Snake

${ }^{4}$ Template matching

${ }^{5}$ Multiple hypothesis tracking (MHT)

${ }^{6}$ K-Shortest Paths Optimization
} 
كزارش شده است.

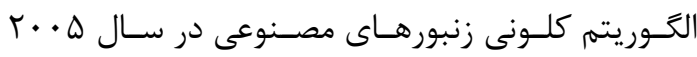

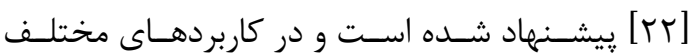

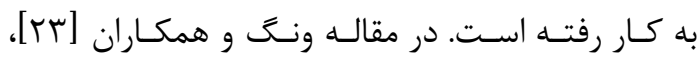

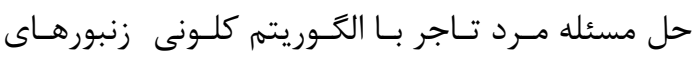
مصنوعى و بهكـاركيرى روشـهايى در ييشــنهاد جوابهـا بلمنظور كاهش حجم محاسبات بهبود داده شده اسـت.

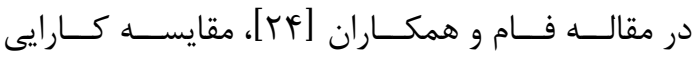
الكوريتم كلونى زنبورهاى مصنوعى بَ با الكوريتم اجتماع معاع

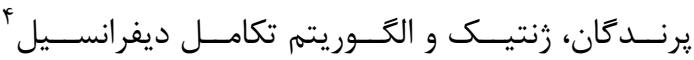
روى يكسرى توابع با ابعاد مختلف صورت كرفتـهـ اسـت.

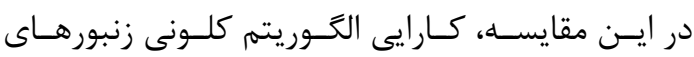

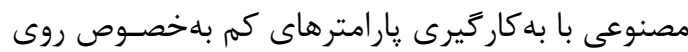

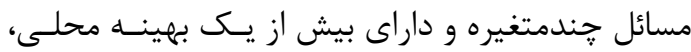

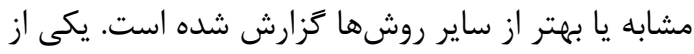

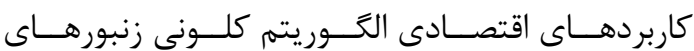

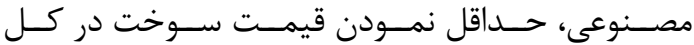
واحدهاى توليدى است كه با اعمال يكسرى قيود توسط

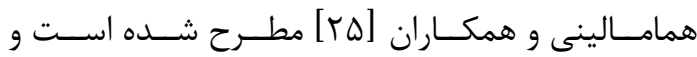

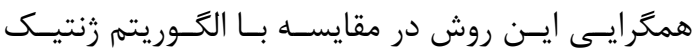

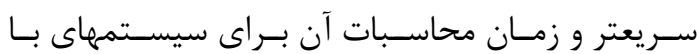
مقياس بالا كمتر كزارش شده است. در تحقيق ديخـرى

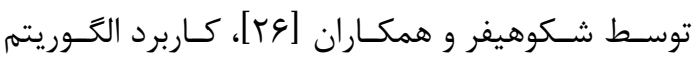
كلونى زنبورهـاى مصـنوعى در يـردازش تصـوير شـامل

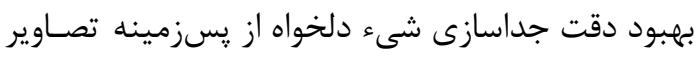

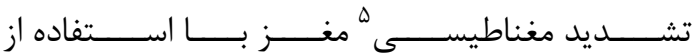

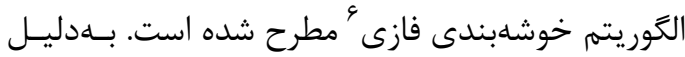

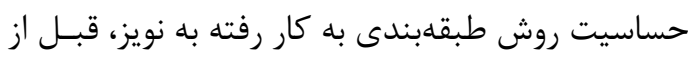

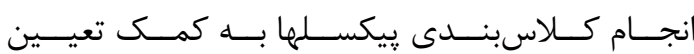

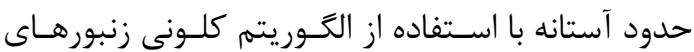
مصنوعى به دو دسته نويزدار و نرمال تفكيك شـدهانـد.

\footnotetext{
${ }^{3}$ Artificial bee colony

${ }^{4}$ Differential evolution

${ }^{5}$ Magnetic resonance imaging (MRI)

${ }^{6}$ Fuzzy C-Means
}

رديابى شدهاند. از سال ه99 199 تا امروز توانايى الحَــوريته

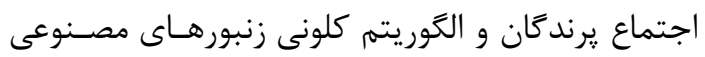

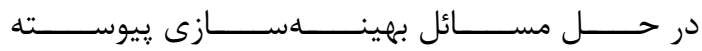

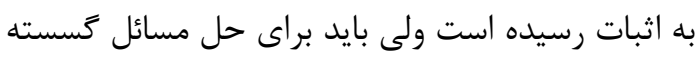

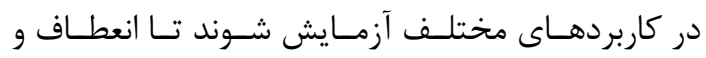

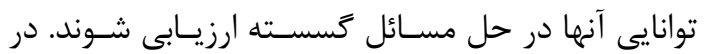

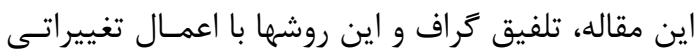

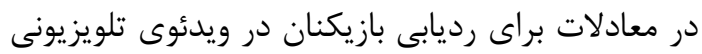
مسابقات فوتبال به كار برده شده است.

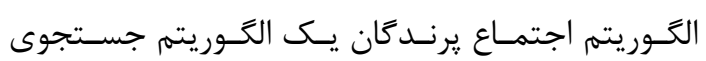
جمعى است كه از رفتارهاى اجتمـاعى كـروه يرنـدكان

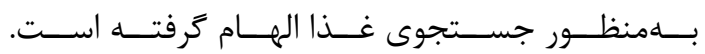

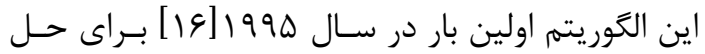
مسائل بيوسته مطرح شده است و مدل كردن رفتارهاى

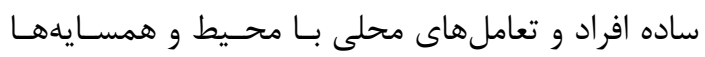

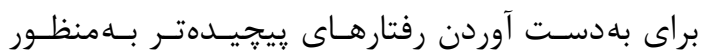
حـل مســئله، مقصـود آن در نظـر كرفتـهـ شـــه اسـت.

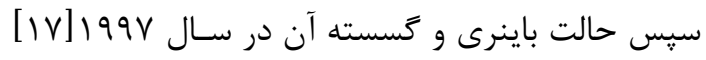

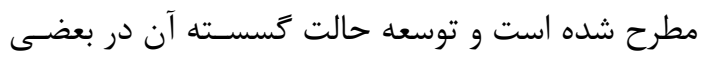

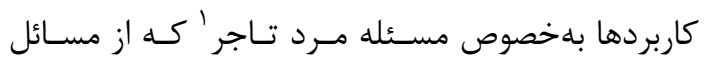

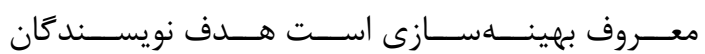

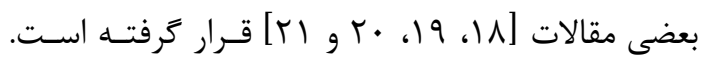

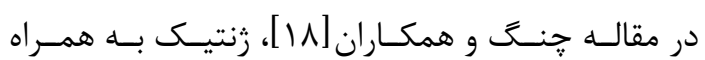

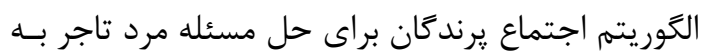

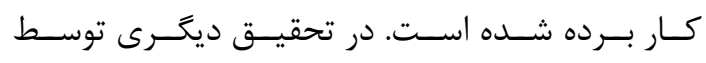

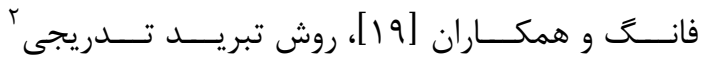

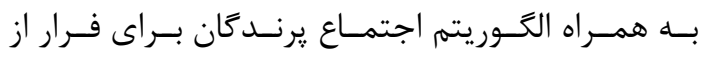

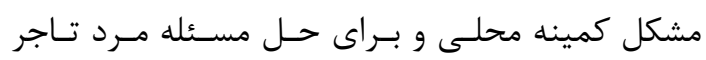
در حال سفر استفاده شدهاند و نتـايج روش تركيبسى بـا روشهاى الكوريتم اجتماع يرندكان، الكَوريتم مورجههــا و تبريد تدريجى مقايسه شـدهانـد كـه در ايـن مقايسـهـ

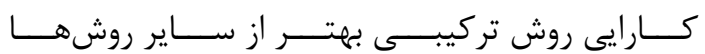

${ }^{1}$ Travelling salesman problem (TSP)

${ }^{2}$ Simulated annealing 
در نظــر خــرفتن ارتبـاط آنهاسـت. در مرحلـهـ رديـابى،

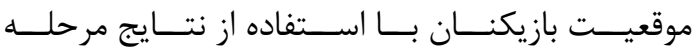

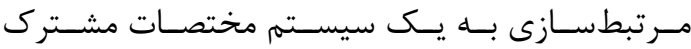
منتقل شده است. سيس، گراف همسايكى با اسـتفاده از

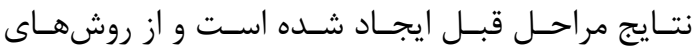
هوش مصنوعى براى استخراج مسيرهاى بهينه بازيكنان در گراف همسايكى استفاده شده است. تصاوير متوالى ويدئو

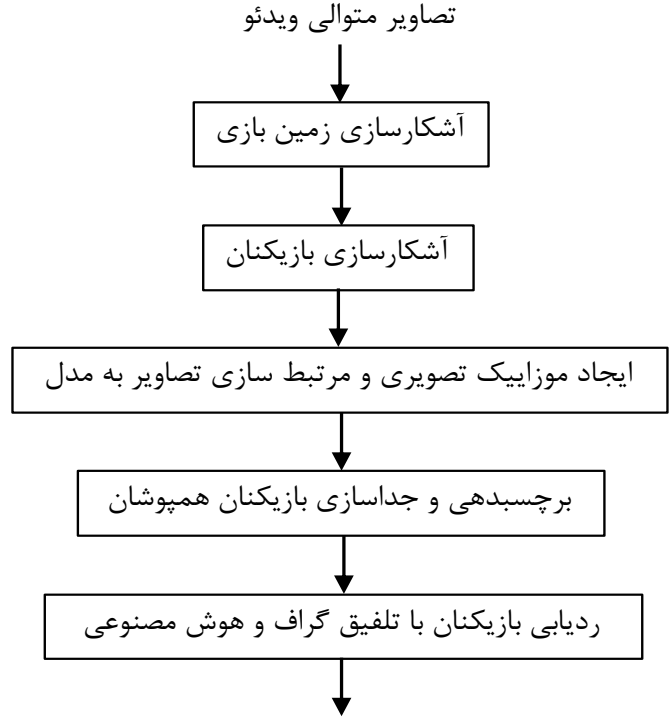

مسير حركت بازيكنان روى موزاييك تصاوير و مدل زمين شكل ا: روندنماى رديابى بازيكنان

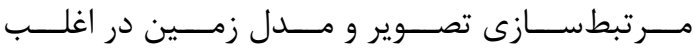

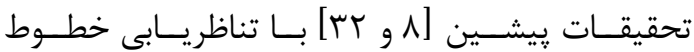

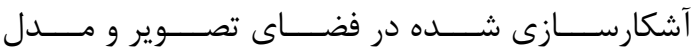

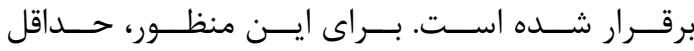
دو خـط عمــودى و دو خـط افقـى متنــاظر در دو فضـا

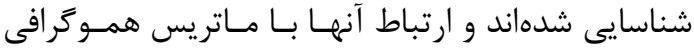
برقرار شـده اسـت. بـهمنظــور يـافتن خطـوط متنــاظر،

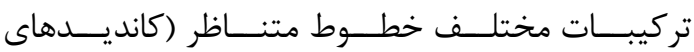
تناظريابى) ارزيابى شدهاند و بهتـــين كانديسد (دو خـط متناظر افقىى و دو خــط متنـاظر عمــودى كـهـ بهتـرين ارتباط را بين دو فضا برقرار كردهاند) انتخاب شده است.

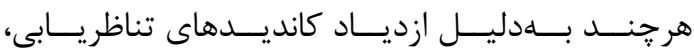
تركيبـات زيــادى در ايـن روشهـــا ارزيـابى شــدهانــد.

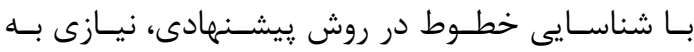

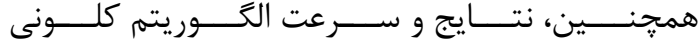
زنبورهاى مصـنوعى در مقايسـهـ بـا زنتيـك و الخــوريتهم مورجهها بهببود يافته است. الخـوريتم كلـونى زنبورهـاى مصنوعى، در بهبود عمليـات دفـاع بـهمنظــور حفاظـت

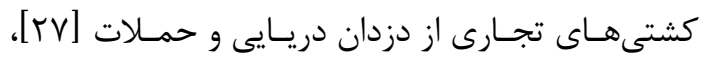

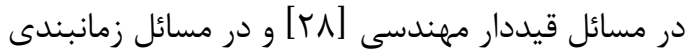

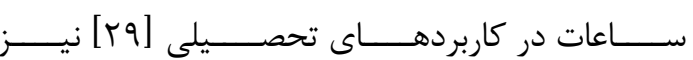
مطـــرح شــــده اســـت. همجٍنــــين، ايســن روش در كاربردهاى صنعتى بامنظور كاهش زمان انجام عمليـات توسط ماشينها توسط نويسندگًان بعضى مقالات [ •" و

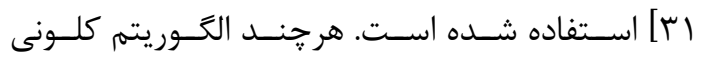
زنبورهاى مصنوعى اغلب براى مسائل ييوسـته بـهـ كـار رفته اسـت ولـى مـى توانـد بـراى مســائل كسســــ نيـز به كار برده شود.

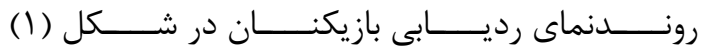
نشان داده شده اسـت. ورودىهـاى مــورد نيـاز مرحلـه رديه رديـابى (موقعيـت بازيكنــان، تـيم بازيكنــان، موزايـــ تصويرى و مرتبطسازى تصاوير با مدل) در جهار مرحله

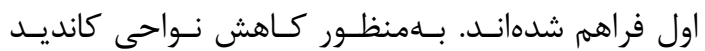
بازيكن و حذف نواحى جمن و خارج زمين، ابتدا زمسين

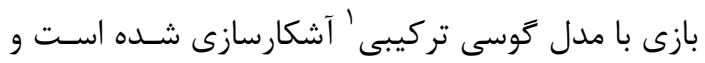

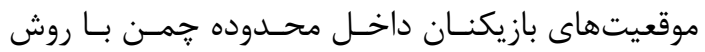

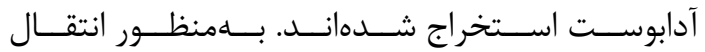

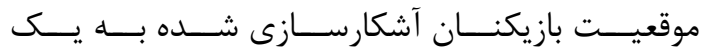

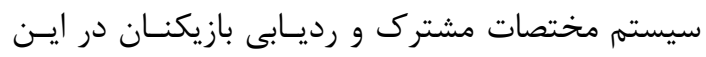

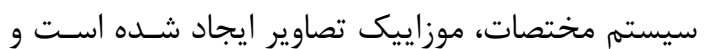

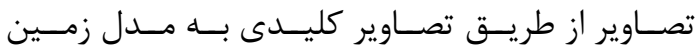
مــرتبط شـدهانـد (مــرتبطســازى ' تصــوير و مــدل). در مرحله بعد، برجسبدهى (تعيـين تـيهم) بازيكنـان و و

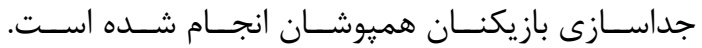

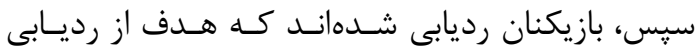

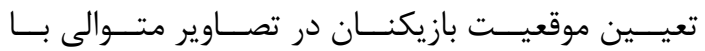

${ }^{1}$ Gaussian mixture model (GMM)

${ }^{2}$ Registration 
روش مــدل كوسـى تركيبـى و بازيكنـان بـا آدابوسـت آشكارسازى شدهاند. سيس، ايجاد موزاييكى تصـويرى و و رو

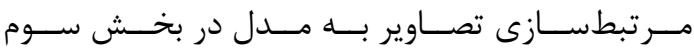
مطرح شدهاند. در بخـش جههارم، جداسـازى بازيكنـان

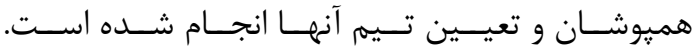

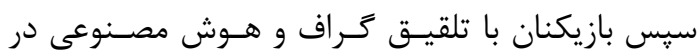

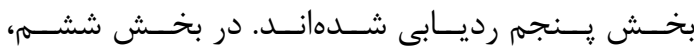

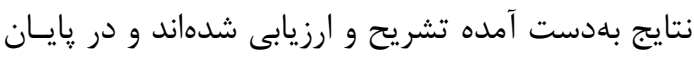

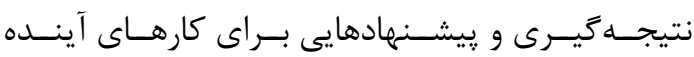
مطرح شده است.

\section{r- آشكارسازى زمين جمن و بازيكنان}

از آنجــا كــهـ بازيكنــان در تصـاوير ويـــئويى فوتبــال داخل ناحيه جمن (رنخ غالب يسزمينه در ويـدئوهاى

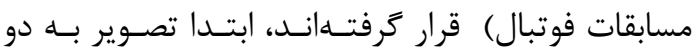

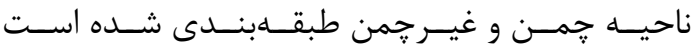
(آشكارسازى زمين جمن). در اين راسـتا، مــدل كوسى

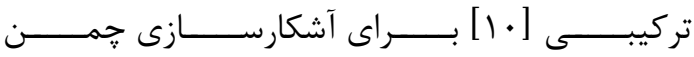
استفاده شده است كه نيـاز بــهـ آمـوزش نــــارد و نتــايج قابل قبول بهعنوان ورودى مراحل بعد ارائسه داده اسـت.

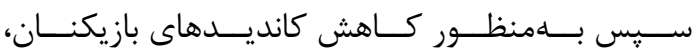
نواحى يسزمينه (تماشاگرها، خارج جمـنـ) بـا تشـكيل

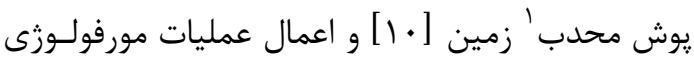

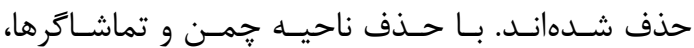

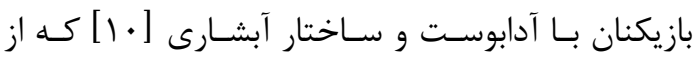
روشهاى سريع طبقهبندى است آشكارسازى شدهاند.

\section{r- ايجــاد موزاييـــ تصــويرى و مـــتبطســازى}

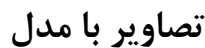

بهمنظور انتقال موقعيت بازيكنان آشكارسازى شـده بــهـ يك سيستم مختصات مشـترك و رديـابى بازيكنـان در اين سيستم مختصات، موزاييك تصاوير ايجاد شده است

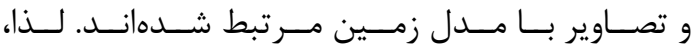

${ }^{1}$ Convex hull
آزمايش تركيبـات مختلـف تناظريـابى نيست و تعـانداد

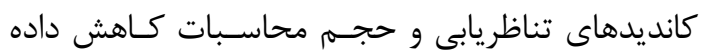
شدهاند. همجنين بلمنظور كاهش خطاهـاى تجمعى و

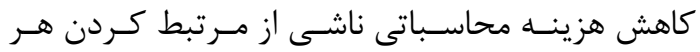

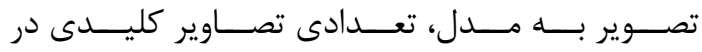

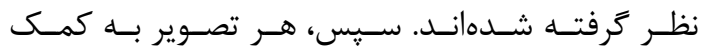
نزديكترين تصوير كليدى به مدل مرتبط شده است كـهـ

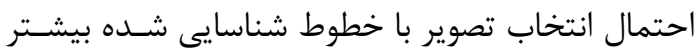
بهنوان تصوير كليدى بيشتر است. در روش رديابى براساس كراف، يك كراف با اسـتفاده از

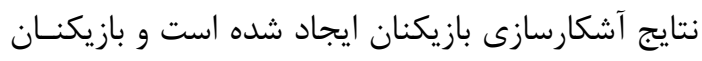

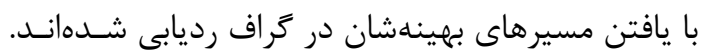
بنابراين، بازيكنان آشكارسازى شده در تصاوير متوالى با باديا

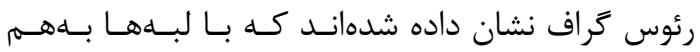

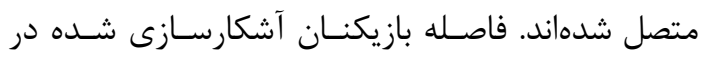

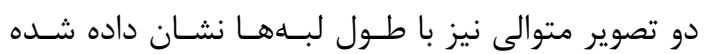

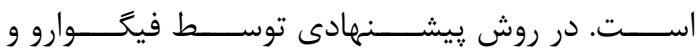

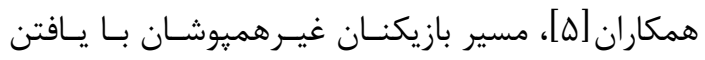
كوتاهترين مسير مشخص شده است. در اين روش، خند

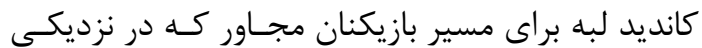

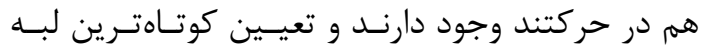

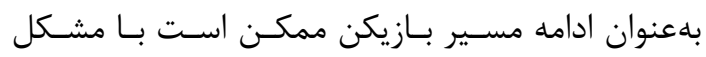

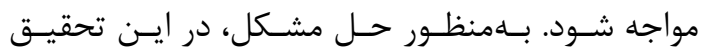

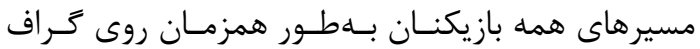
تعيين شدهاند تا ابهامات در مورد مسير بازيكنان مجاور

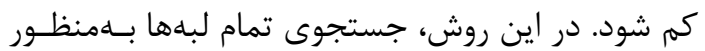
تعيين مسير بازيكنان از نظر محاسباتى يرهزينه است و

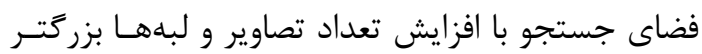

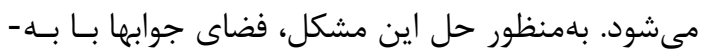
كارگيرى روشهاى هوش مصنوعى جستجو شده است.

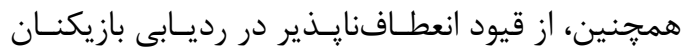

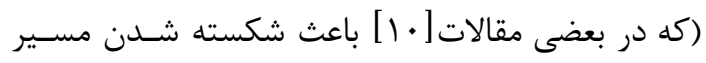
بازيكن به جند قسمت شده است) اجتناب شده است.

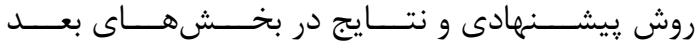

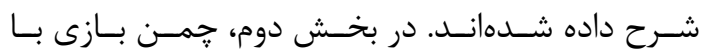




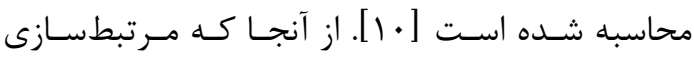

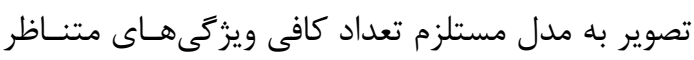

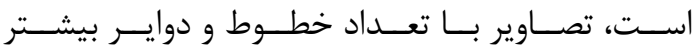
(مثلا تصاوير ناحيـهـ پنـالتى و وسـط زمـين) بـهـعــــان

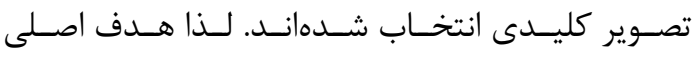

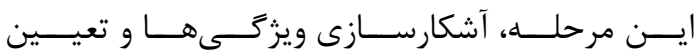

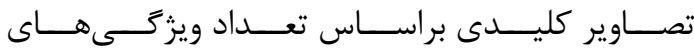

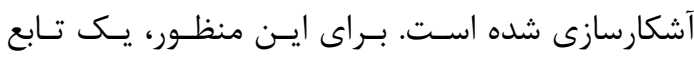

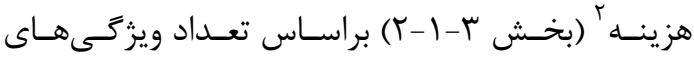
آشكارسازى شده در تصوير تعريف شده است كه هر خه مقدار تابع هزينه كمتر باشـد، احتمــال انتخــاب تصـوير

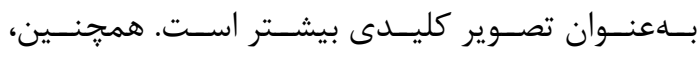

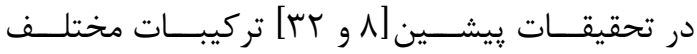

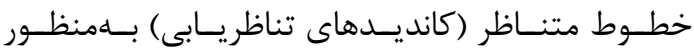

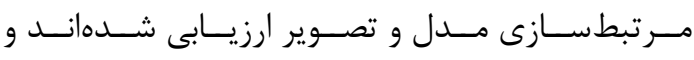

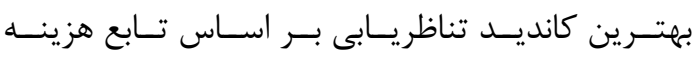
انتخاب شده است. هر جند بهدليـل ازديـاد كانديـدهاى

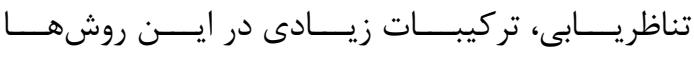

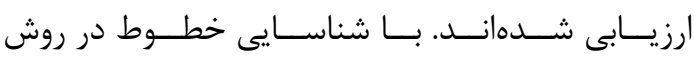

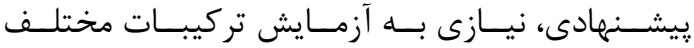

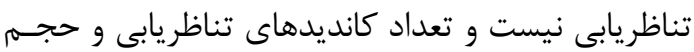
محاسبات كاهش داده شدهاند.

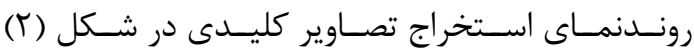

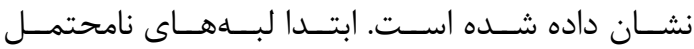
بلهنظور آشكارسازى خطوط حذف شدهاند. لذا، بعـد از

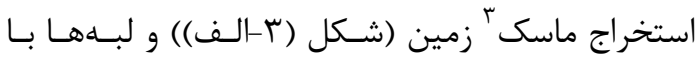

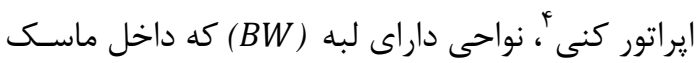

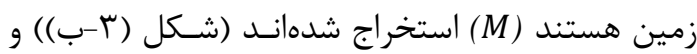

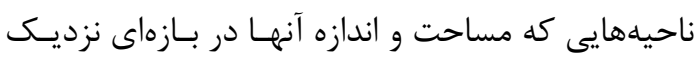

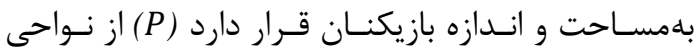
استخراج شده حذف شدهاند. سيس، محدوده دور زمين

\footnotetext{
${ }^{2}$ Cost function

${ }^{3}$ Mask
}

${ }^{4}$ Canny

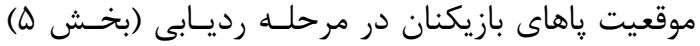

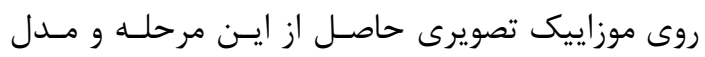
زمين نمايش داده شدهاند. از آنجا كه انتقال بين تصاوير با يكديكر و با مدل بين دو صفحه است (يـاى بازيكنـان

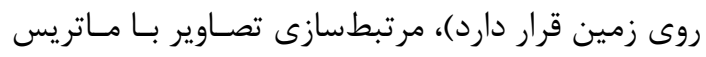

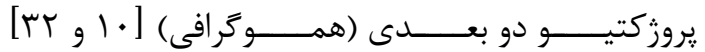

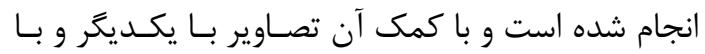
مدل زمين مرتبط شدهاند. بلمنظور مرتبطسازى تصاوير و ايجاد موزاييك تصويرى، مدئ

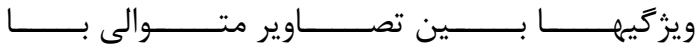

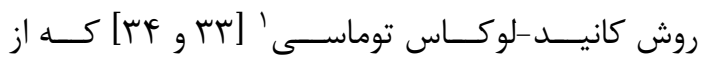

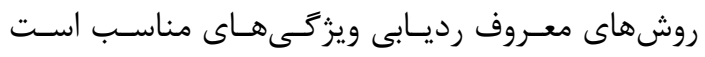

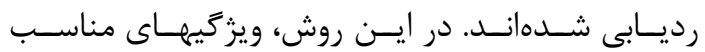

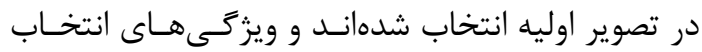

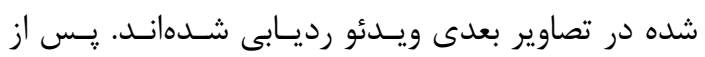
رديابى ويزَّىها، ماتريس انتقال بين تصاوير با اسـتفاده

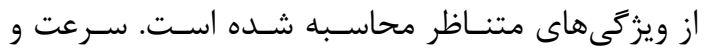

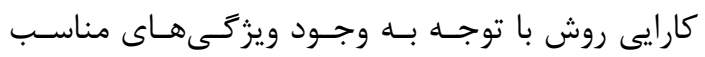
فراوان در ناحيه تماشاكرها و تابلوهاى تبليغاتى مناسـب

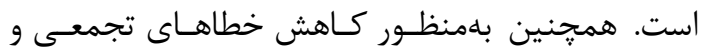

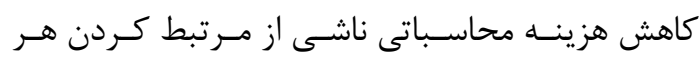

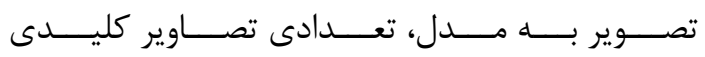
در نظر كرفته شدهاند و هر تصوير به كمك نزديكترين

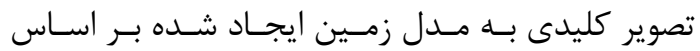
استانداردهاى فيفا مرتبط شده است.

\section{ب-1- انتخاب تصاوير كليدى}

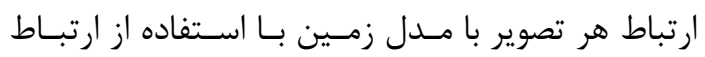

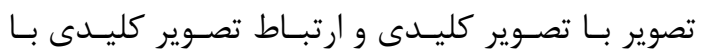
مدل زمين برقرار شده اسـت. بـهمنظـور مـرتبطســازى

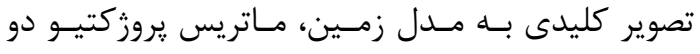

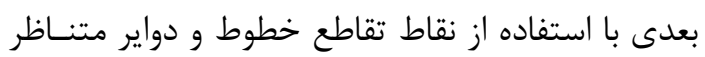
(ويرگى هاى متناظر) در تصـوير كليـدى و مـدل زمسين

\footnotetext{
${ }^{1}$ Kanade-Lucas-Tomasi feature tracker (KLT)
} 


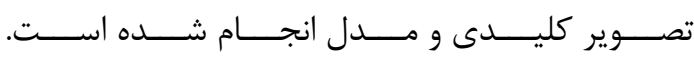

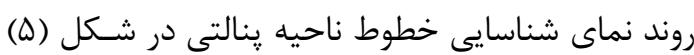

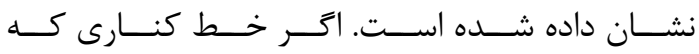
نمايانكر تصاوير كنارى زمسين اسـت آشكارسـازى شـده لئه

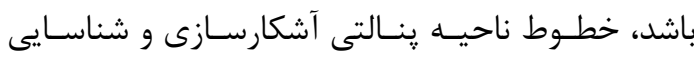

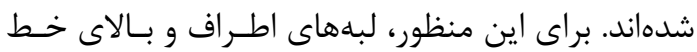

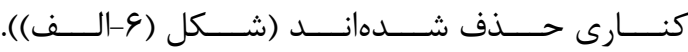
سيس، دو خط عمودى به موازات خط كنـارى بـا هـاف

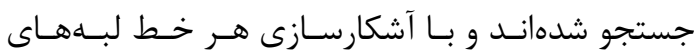

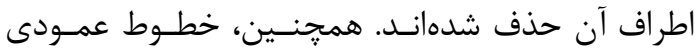

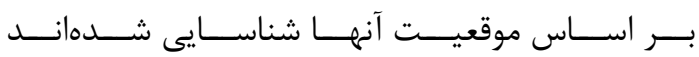
(مثلا خط عمودى نزديكتر به خط كنارى، خط عمودى اله

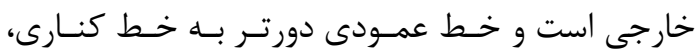

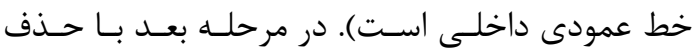

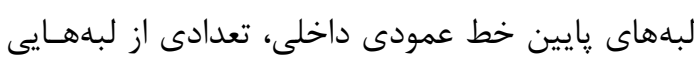

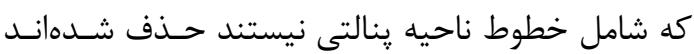

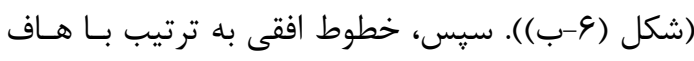

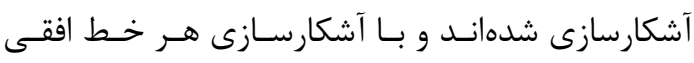

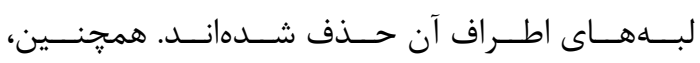

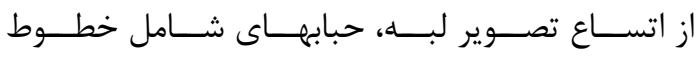

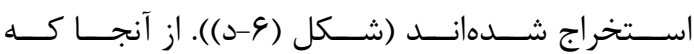
خطوط آشكارسازى شده با هاف (شكل( צ-ج)) ابتـدا و

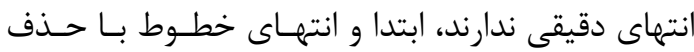

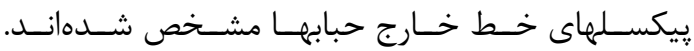

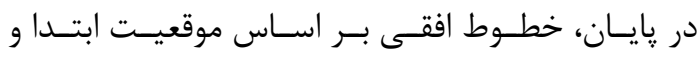
انتهاى آنها نسبت به خطوط حمودى شناسايى شدهاند.

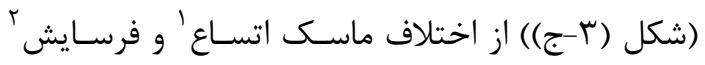

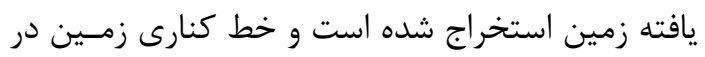

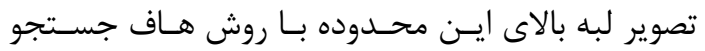
شده است (شكل (r-د)). در صورت آشكارسـازى خـط

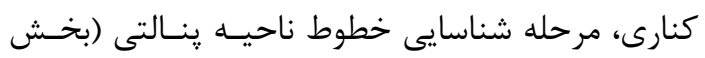
r-1-1) با هدف تعيين تصاوير ناحيه دروازه و كـاهش

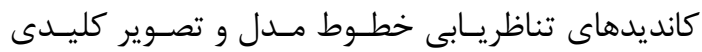

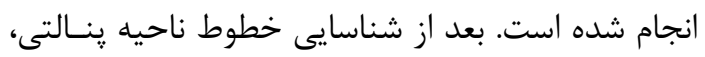

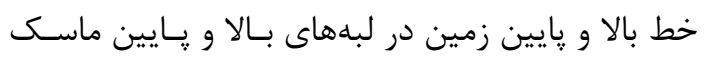

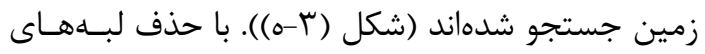

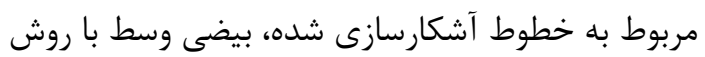

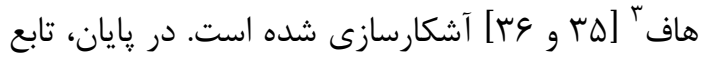

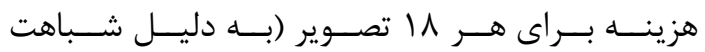
تصاوير نزديك به همم) محاسبه شده اسـت و تصـوير بـا

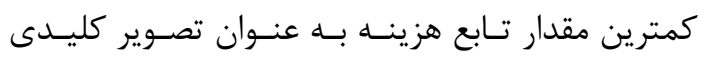

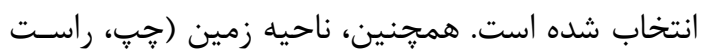

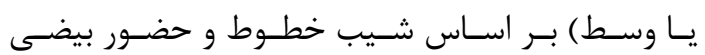
شناسايى شده است.

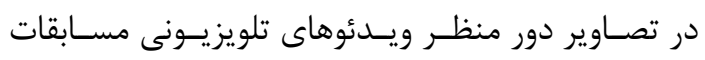

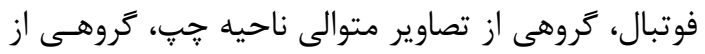

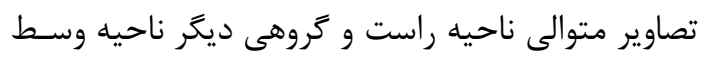

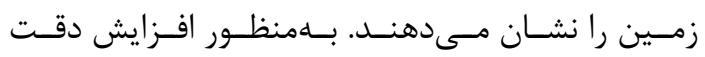
مرتبطسـازى، در صـورت تغييــر ناحيـهـ زمــين مــثلا از

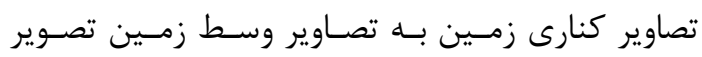

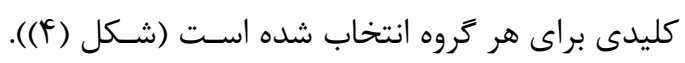

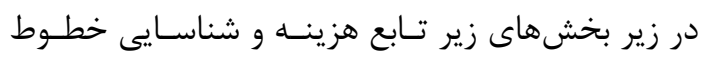
ناحيه ينالتى شرح داده شدهاند.

\section{r-1-1- شناسايى خطوط ناحيه پينالتى}

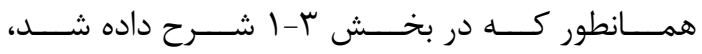

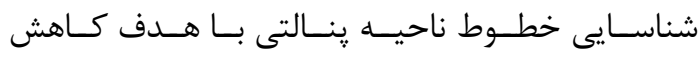

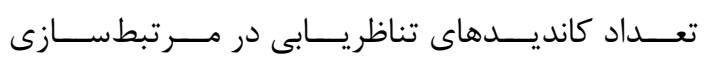

${ }^{1}$ Dilation

${ }^{2}$ Erosion

${ }^{3}$ Hough transform 


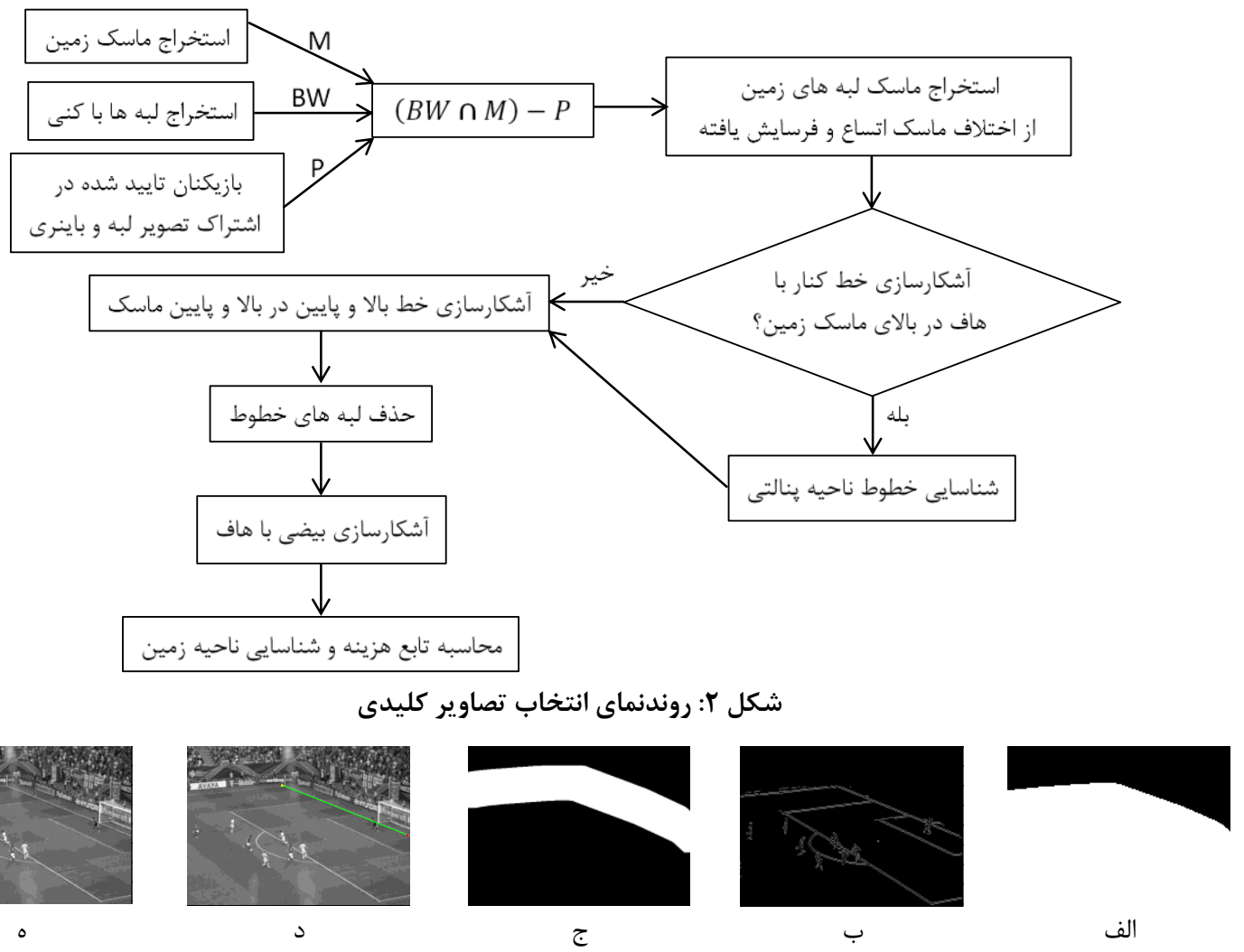

شكل ץ: الف) ماسك زمين، ب) لبه هاى داخل ماسك زمين، ج) اختلاف ماسكهاى اتساع وفرسايش يافته، د) خط كنارى زمين، ه) خط بالاى زمين

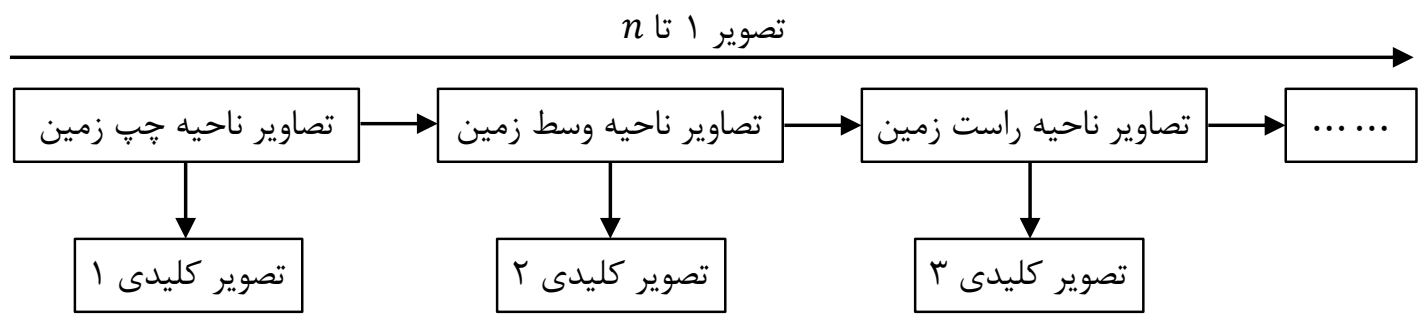

شكل F: انتخاب تصاوير كليدى در بخشهاى مختلف ويدئو 
رديابى بازيكنان در تصاوير ويدئويى مسابقات فوتبال با...

مهرتاش منافى فرد، حميد عبادى، حميد ابريشمى مقدم

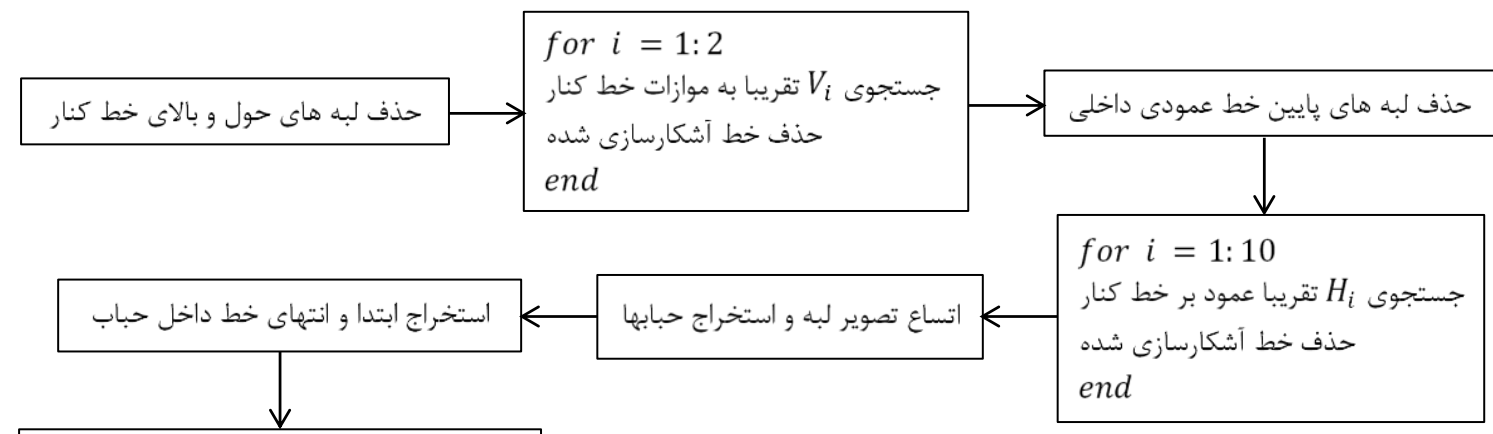

شناسايى موقعيت خطوط افقى نسبت به عمودى

بر اساس فاصله نقاط ابتدا و انتهاى آنها از هم نم

شكل ه: روندنماى شناسايى خطوط ناحيه بنالتى

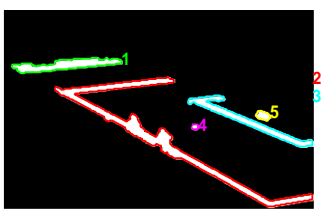

(د)

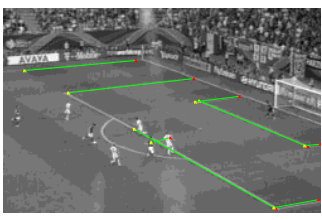

(ج)

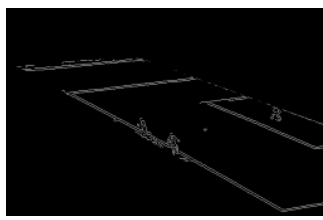

(ب)

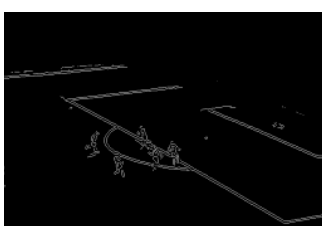

(الف)

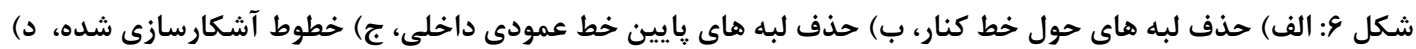
حبابهاى شامل خطوط

آشكارسازى بيضى كـاهش مسى يابـد. در نتيجـهـ مقـدار

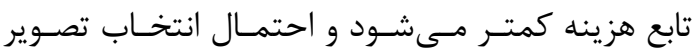
بلهنوان تصوير كليدى افزايش مىيابد.

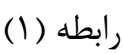

cost $=w_{1} \times w_{2}$

$w_{1}=\frac{1}{K\left(n v^{r}+n h^{r}\right)+N}$,

$K=$

$\begin{cases}1000, & \text { if } n v^{r} \geq 2 \text { and } n h^{r} \geq 2 \\ 10, & \text { if } n v^{r}<2 \text { and } n h^{r}<2 \\ \frac{1}{\left(n v^{r}+n h^{r}\right)}, & \text { if } n v^{r}+n h^{r}+N=0\end{cases}$

$w_{2}=\left\{\begin{array}{cl}\frac{1}{1000}, & \text { if } n^{e}=1 \\ 1, \quad & \text { else }\end{array}\right.$

همجنين، مقدار w1 با افـزايش تعـداد خطـوط افقـى و عمودى شناسايى شده كاهش مى يابد. در نتيجه مقـدار

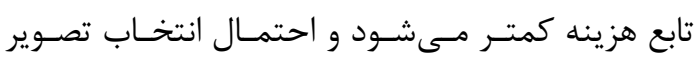

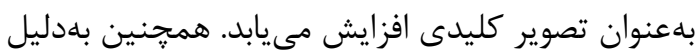

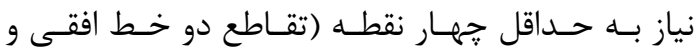

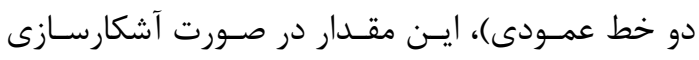

r-1-r- تابع هزينه به منظور اســتخراج تصــاوير كليدى همانطور كه در بخش بـ-1 شـرح داده شـد، يـك تـابع

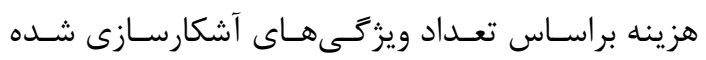
تعريف شده است كه هر جه مقدار تابع هزينه مربوط به تصوير كمتر باشد، احتمال انتخاب آن بهعنـوان تصـوير

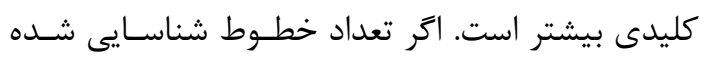
بيشتر باشد يا بيضى در تصوير آشكارسازى شود، مقـدار

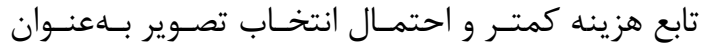
تصوير كليدى بيشتر است. بـه منظــور انتخــاب تصـاوير

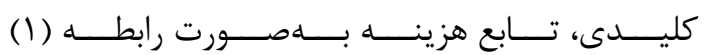
تعريف شده است: تعداد كل خطوط آشكارسازى شده، تعداد خطوط افقىى تُه شناسايى شده و تعداد خطوط عمودى شناسـايى شـده

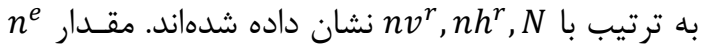
در صورت وجود بيضى وسط يكى و در غير ايسنصـورت

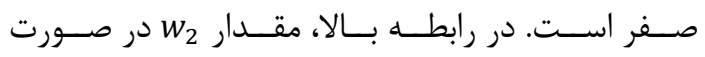


توسط منافى فرد و همكاران[ [ [] بـهمنظــور جداسـازى

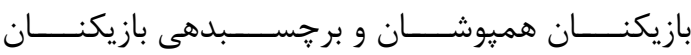
استفاده شده است.

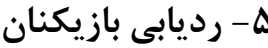

يس از آمادهسازى ورودىهاى رديابى در مراحـل قبـل،

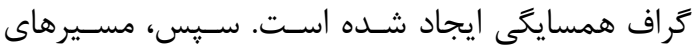

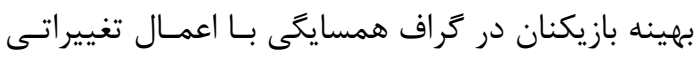
در نحوه بهروزكردن موقعيت و سرعت ذرات با الكَوريته

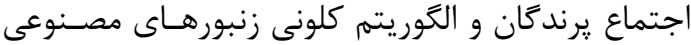

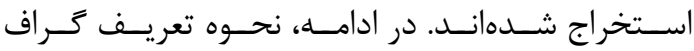

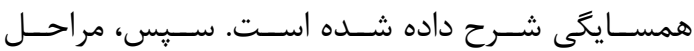
طى شده براى استخراج مسـيرهاى بازيكنـان در كـراف

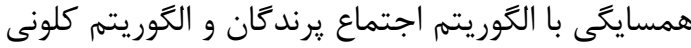
زنبورهاى مصنوعى شرح داده شده است.

\section{ه-1- تعريف همسايگى}

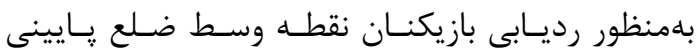

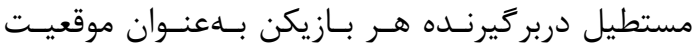
بازيكن در نظر گرفته شده است. همجنين، با استفاده از

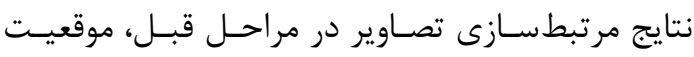
بازيكنان به سيستم مختصات مشترك (مدل يا سيستم مختصات تصوير اول) منتقل شدهاند. سـيس بــهمنظــور آمادهسازى ورودى هاى مرحله رديابى، كراف همسـايكى آنى با رابطه زير تعريف شده است:

حداقل دو خط افقى و عمودى بيشتر كاهش مى يابد تـا

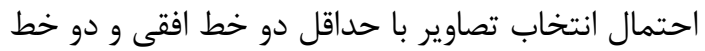
عمودى بهعنـوان تصـوير كليـدى بيشـتر شـود. بعـد از

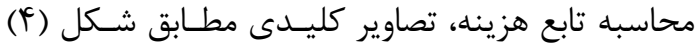
انتخاب شدهاند. در روش ييشنهادى، تعداد كانديـدهاى تناظريابى بين مدل و تصوير كليدى با شناسايى خطوط به مقدار قابل توجه كم شده است.

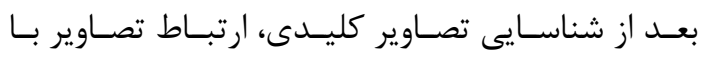
نزديكترين تصوير كليدى با انتقال بروزكتيـو دو بعـدى إنى محاسبه شده است. ارتباط تصاوير كليدى با مدل زمين

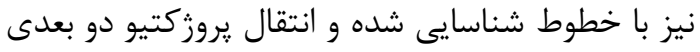
برقرار شده است. در نتيجه با معلوم بـودن انتقـال بـين تصوير كليدى با مدل زمين و تصاوير با تصوير كليسدى، ندري، هر تصوير با مدل مرتبط شده است [بَّ].

\section{F- بر קسبدهى و جداسازى بازيكنان هميوشان}

در ويدئوى مسابقات فوتبال، هميوشـانى بــين بازيكنـان بلويزه بازيكنان حريف بهدليل حركت نزديك دو بازيكان

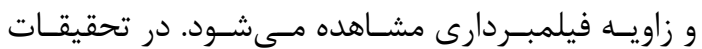

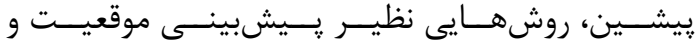

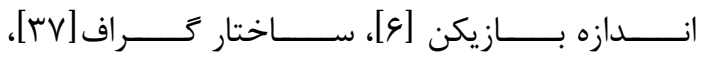

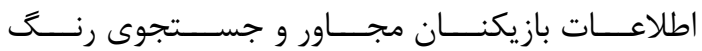

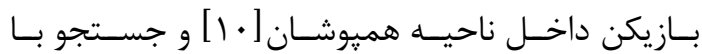

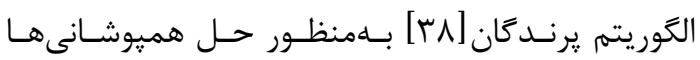
استفاده شـدهانـد. در ايـن مرحلـه، از روش ارائـهـ شــده

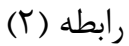
$N=\left\{\left\|Y_{t_{i}}^{i}-Y_{t_{j}}^{j}\right\| \leq\left\|t_{i}-t_{j}\right\| \times V_{v}^{\max },\left\|X_{t_{i}}^{i}-X_{t_{j}}^{j}\right\| \leq\left\|t_{i}-t_{j}\right\| \times V_{h}^{\max },\left\|t_{i}-t_{j}\right\| \leq \Delta t^{\max }\right\}$

بازيكن و در تصوير بعد بهعنوان فرزند بازيكن در تصوير جارى تعريف شده اسـت. بعـد از تعريـف همســايكى دهــا

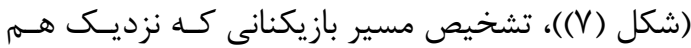

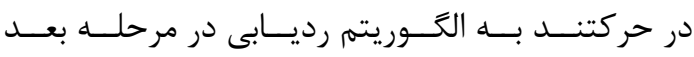
واكذار شده است.
موقعيـت بـازيكن i در تصـوير t بـا

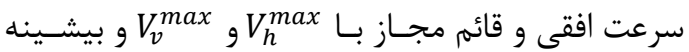
اختلاف زمانى مجاز بين دو بازيكن همسـايه بـا

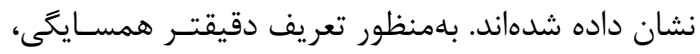
شرط بالا در دو فضاى تصوير و مدل بررسى شده اسـت.

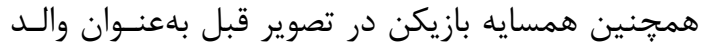




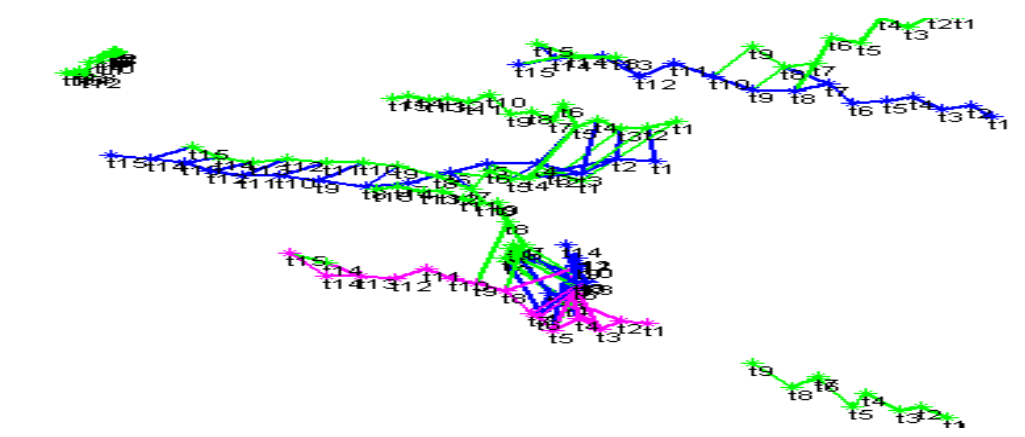

شكل V: همسايغى در فضاى تصوير (آبى: بازيكنان تيم ا، سبز: بازيكنان تيم Y، صورتى: داور)

رفتارهاى فردى و اجتماعى بلهروز مسى گردد و موقعيـت

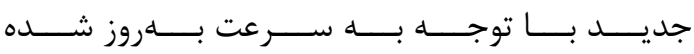

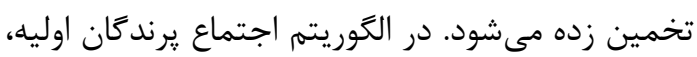

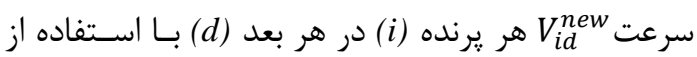
رابطه (ז) بهروز شده است:

$V_{i d}^{\text {new }}=w_{i} \cdot V_{i d}^{\text {old }}+c_{1} \cdot r_{1} \cdot\left(P_{i d}-x_{i d}\right)+c_{2} \cdot r_{2} \cdot\left(P_{g d}-x_{i d}\right)$

P Pd

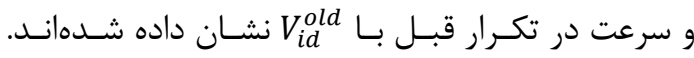

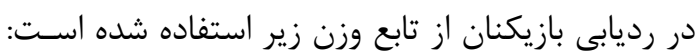

$w=w_{-} \max -\left[\left(w_{-} \max -w_{-} \min \right) \times\right.$ iter $] / \triangle \max \nabla_{-}$iteration (يرندهها) بهصورت ماتريس موقعيت، مقـداردهى اوليـهـ ذرات (تعيين موقعيت و سرعت اوليه هر ذره)، تغييـرات

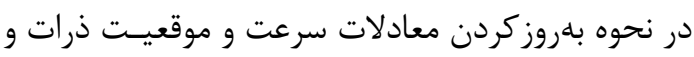
تابع برازندىى مورد استفاده شرح داده شده است.

$$
\text { ه-r-1- ا- ماتريس موقعيت }
$$

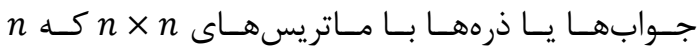

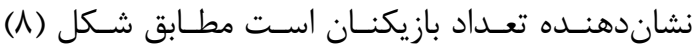
نشـان داده شــدانـد. همجزنـين بازيكنــان همســايه در تصوير قبل و بعد بهترتيب بهعنوان والد و فرزند بـازيكن در تصوير جارى در نظر گرفته شدهاند. بلهمنظـور ايجـاد

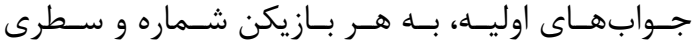

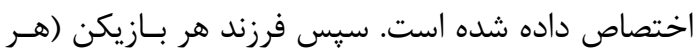
سطر) با اختصاص مقدار يك به ستون مربوط به فرزنـد

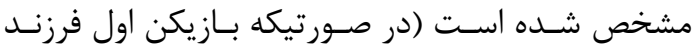

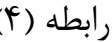
كه بيشينه و كمينه مقدار w بـا

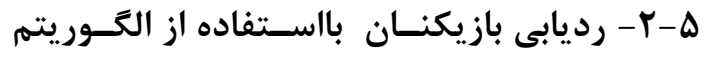
اجتماع يرندَان بهبود يافته در الكوريتم اجتماع يرندگان، ذرهها به سـمت موقعيـت بهينه حركت مى كنند و حول جواب بهينه فضاى زيادى جستجو مىشود. هر يرنده موقعيت و سرعت مخصـوص

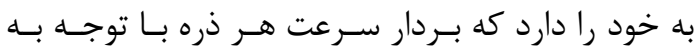

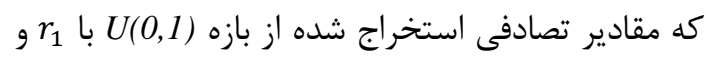
ro $r_{2}$ در فضاى d بعدى با Xid، بهينه محلى (بهترين موقعيت

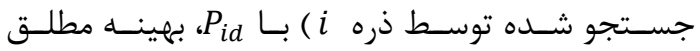

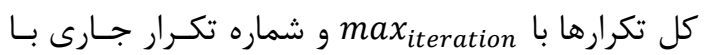
iter از سرعت محاسبه شده بهروز شده است:

$$
x_{i d}=x_{i d}+V_{i d}
$$

در سال 199V ، الكوريتم فوق براى حل مسائل گسسـته

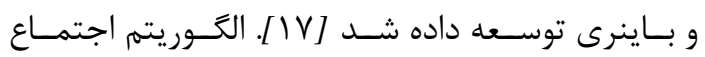

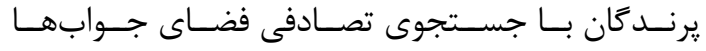
(جستجوى تصادفى مسيرهاى بهينه بازيكنان در خـراف

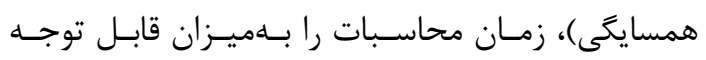
كاهش مى دهد. در زيربخش هاى زير، الخـوريتمم اجتمــاع يرندگان بهمنظور رديابى بازيكنـان در ويــئوى فوتبـال

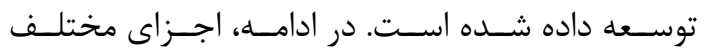
الكوريتم اجتمـاع يرنـدَّان شـامل نحـوه نمـايش ذرات 


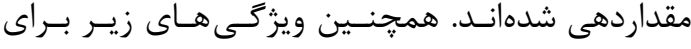
ايجاد ماتريسهاى موقعيت ذرات در نظر كرفته شدهاند:

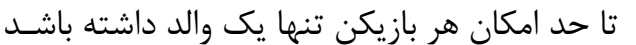
يا توسط يك والد انتخاب شود.

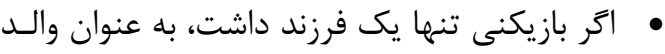
آن فرزند انتخاب شود. ماتريسهاى صفر $n$ × ذرات اختصاص داده شدهاند. ه-r-r-r به ب- بروز كردن سرعت

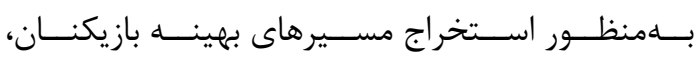

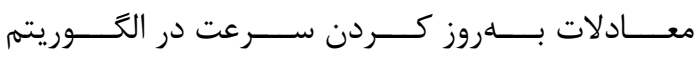
اجتماع يرنـدكان بهبــود داده شـدهانـد. در ايـن راسـتا،

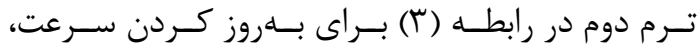

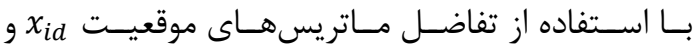
موقعيت بهينه محلى Pid محاسبه شده است: $P_{i d}-x_{i d}=\left[\begin{array}{ccc}0 & \cdots & 1 \\ \vdots & \ddots & \vdots \\ 1 & \cdots & 0\end{array}\right]-\left[\begin{array}{ccc}1 & \cdots & 0 \\ \vdots & \ddots & \vdots \\ 0 & \cdots & 0\end{array}\right]=\left[\begin{array}{ccc}-1 & \cdots & 1 \\ \vdots & \ddots & \vdots \\ 1 & \cdots & 0\end{array}\right]$

ه-

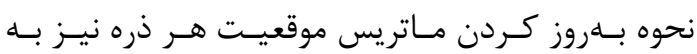
منظور رديـابى بازيكنـان تغييـر داده شـده اسـت. لـذا، بازيكنى كه فرزند آن بيشينه سرعت را در سطر مربـوط

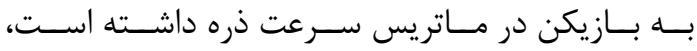

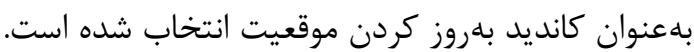
كانديدها در شكل (9) با رنگ قرمز نشان داده شدهاند.
بــازيكن دوم باشــد، در ســـر دوم و ســتون اول يـــ قرار داده شده است).

\begin{tabular}{|c|c|c|c|c|c|c|}
\hline & $P 1$ & $P 2$ & $P 3$ & $\ldots$ & $\cdots$ & $P n$ \\
\hline$P 1$ & 0 & 0 & 0 & 1 & 0 & 0 \\
\hline$P 2$ & 1 & 0 & 0 & 0 & 0 & 0 \\
\hline P3 & 0 & 0 & 1 & 0 & 0 & 0 \\
\hline & 0 & 1 & 0 & 0 & 0 & 0 \\
\hline & 0 & 0 & 0 & 0 & 1 & 0 \\
\hline${ }^{n} n$ & 0 & 0 & 0 & 0 & 0 & 1 \\
\hline
\end{tabular}

شكل ^: ماتريس موقعيت (Pn نشان دهنده بازيكن n ام

$$
\text { است) }
$$

\section{ه-r-r-r- مقداردهى اوليه ذرهها}

جستجو در الكوريتم اجتماع يرندگان با مقداردهى اوليه ذرات (تعيين ماتريس موقعيت و سرعت بـراى هـر ذره) بهطور تصادفى آغاز شده است. براى اين منظور، هر ذره بــا يـك مــاتريس موقعيـت نشــان داده شـده اسـت و و ماتريسهاى موقعيت ذرات با انتخــاب تصـادفى يكـى از

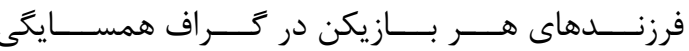

(9)

در مــاتريس بــالا، فرزنــد بــا ســحح اطمينــان يــايين

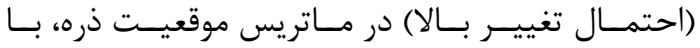

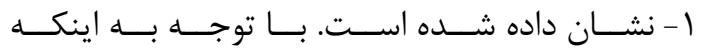
احتمال تغيير فرزند هر بازيكن با ماتريس سرعت نهايى تعيين شده است، مقادير 1- بــا 9. · و بقيـه مقــادير بـا صفر جايگزين شدهاند. همجنين، تـرم سـوم در معادلـه بهروز كردن سرعت، با روشى مشـابه روش بـالا ولـى بــا

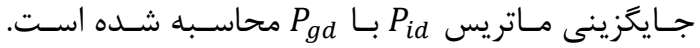

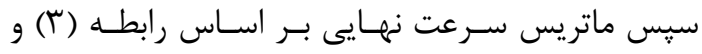

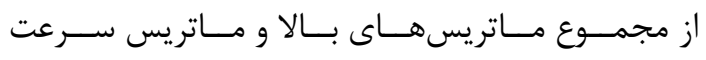

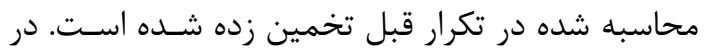
يايان سـرعتهــاى محاسـبه شـده بـا اسـتفاده از تـابع سيخمويد' در بازه [ (, •] قرار گرفتهاند.

${ }^{1}$ Sigmoid Function 
رديابى بازيكنان در تصاوير ويدئويى مسابقات فوتبال با...

مهرتاش منافى فرد، حميد عبادى، حميد ابريشمى مقدم

\begin{tabular}{|c|c|c|c|c|c|}
\hline+ & + & + & 1 & + & + \\
\hline 1 & + & + & + & + & + \\
\hline+ & + & 1 & + & + & + \\
\hline+ & 1 & + & + & + & + \\
\hline+ & + & + & + & 1 & + \\
\hline+ & + & + & + & + & 1 \\
\hline
\end{tabular}

$x_{i d}$

\begin{tabular}{|c|c|c|c|c|c|}
\hline+ &,+ 0 & + &,+ & + & + \\
\hline,+ 9 & + &,$+ \varepsilon$ & + & + & + \\
\hline+ & + &,$+ Y$ & 7 & + & + \\
\hline+ &,$+ A$ & + &,+ 9 & + & + \\
\hline+ & + & * &,$+ \mathrm{V}$ &,$+ A$ & + \\
\hline+ & + & + & + &,+ 7 &,+ 0 \\
\hline
\end{tabular}

$V_{i d}$

شكل 9: ماتريس موقعيت و ماتريس سرعت ذره بهمنظور بررسى كانديدهاى بهروز كردن موقعيت (مقادير قرمز)

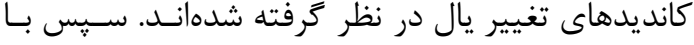

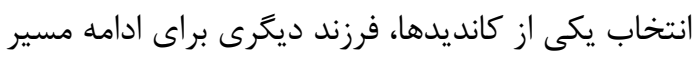
والد بازيكن كانديد انتخاب شده است (ستون ديكرى از باز

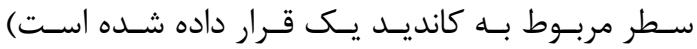

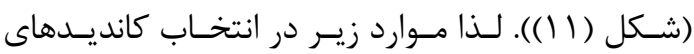
اين حركت در نظر كرفته شدهاند: 1- مجموع سطر و مجموع ستون كانديد در مـاتريس موقعيت بزر كتر از يك باشد.

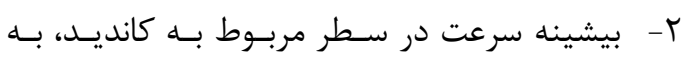
كانديد اختصاص داده شده باشد.

\section{$3 \mathrm{t} 2-1$}

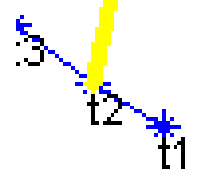

شكل ال: جواب قديمى (زرد) و جواب جديد بيشنهادى

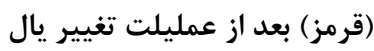

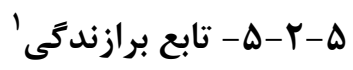

بهمنظور بهروزكـردن مقــادير

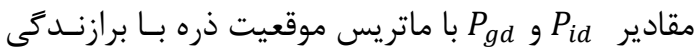
بيشتر از برازندگى

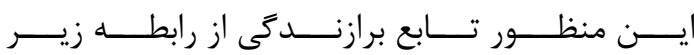

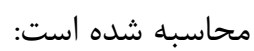

\footnotetext{
${ }^{1}$ Fitness Function
}

در مرحله بعد با دو حركت تعـويض و تغييـر يـك يـال موقعيت ذرهها باروز شدهاند. حركت تعويض: دو بازيكن مختلف با دو فرزند مشترى

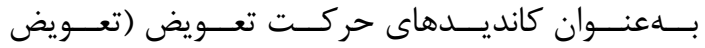
فرزندهاى دو بازيكن) انتخــاب شــدانـــ (شـكل (• ()).

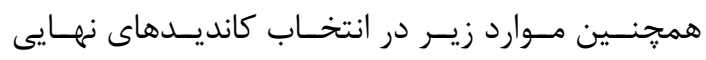
اين حركت در نظر كرفته شده است: • بايد بيشينه سرعت در سطر مربوط به كانديد، بــهـ كانديــد اختصــاص داده شــده باشــــ (احتمـــال

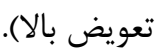

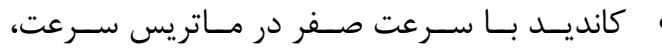
از مجموعه كانديدها حذف شده است.

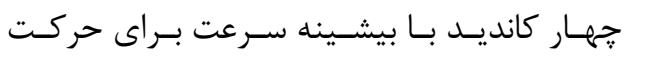
تعويض انتخاب شدهاند. در صورت عدم وجود عنصر غيرصـفر در مـاتريس

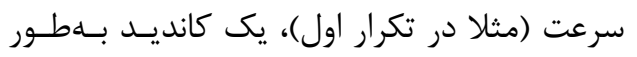
تصادفى براى حركت تعويض انتخاب شده است.

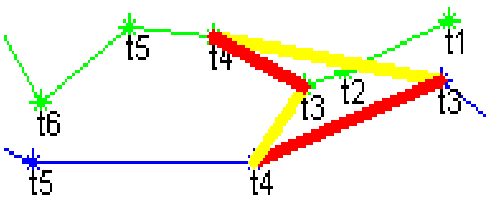

شكل •ا: جوابهاى قديمى (زرد) و جوابهاى جديد ييشنهادى (قرمز) بعد از تعويض تغييــر يــــ يــال: عناصــى از مــاتريس موقعيـت (بازيكنانى) كه والد آنها بيش از يك فرزند داشته اسـت (مجموع سطر مربوط به آن بيش از يك باشد) و توسـ آنسط

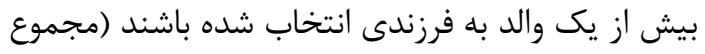

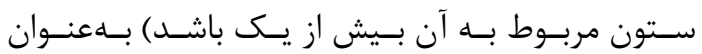


Fitness $=\sum_{i=1}^{N} \frac{1}{\text { Dist }_{i}} \times$ Label $_{i}$

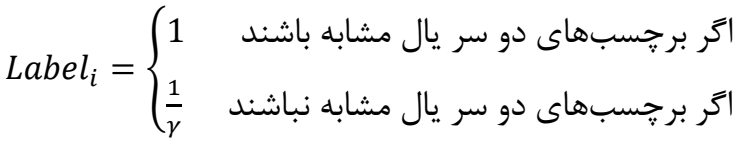

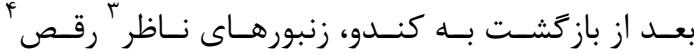

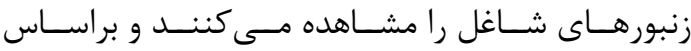
رقص آنها منابع غذايى غنسى تـر شناسـايى مسى شــوند و

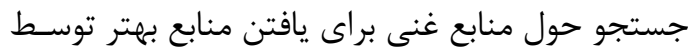

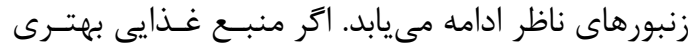

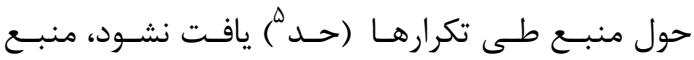

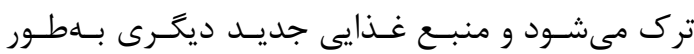

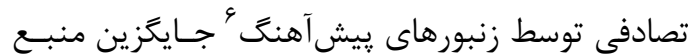
ترك شده مىشود [Tr] يس از انتقال موقعيت بازيكنـان بـهـ سيسـتم مختصـات

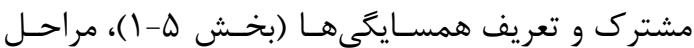

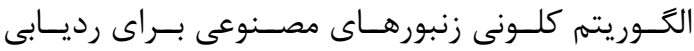
بازيكنها بهصورت زير بيادهسازى شده است:

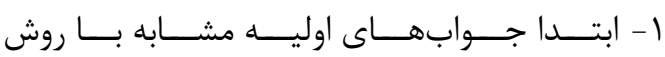

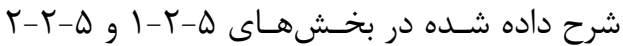
ايجاد شدهاند. براى ايجاد جواب تصادفى ماتريسى

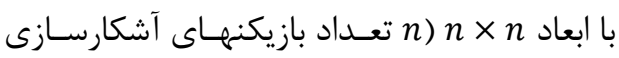

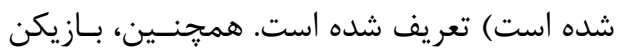
در تصوير قبل بهعنوان والـد و بـازيكن در تصـوير

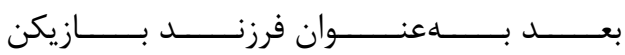
در نظر كرفته شده است و فرزندهـاى بـازيكن در ماتريس تعريف شده با يك نشـان داده شـدهانـد. سـيس، هـر جــواب بــا انتخــاب تصـادفى يكـى از

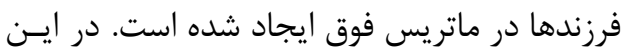
مرحله، منابع غذا (معادل جوابهاى تصادفى اوليه)

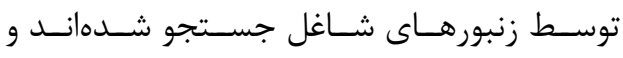

\footnotetext{
3 Onlookers

${ }^{4}$ Waggle dance

${ }^{5}$ Limit

${ }^{6}$ Scout bees
}

كه فاصله بين دو يـال بــا Dist

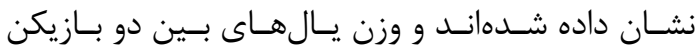
غير همتيمى با پارامتر ه = $\gamma$ كاهش داده شده است. تغييرهاى بالا در مراحل كلى الكوريتم اجتماع يرنـد به شرح زير اعمال شده است:

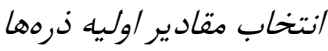

$$
\text { در هر تكرار\} }
$$

براى هر ذره (i) مراحل الف تا ج انجام شلدهاند: الف) محاسبه مقدار برازندكى ذره

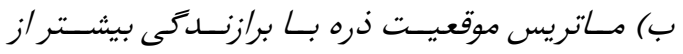
برازندكى است.

ج) مـاتريس موقعيـت ذره بــا برازنــــى بيشــتر /ز

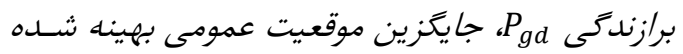
است. بعد /ز انجام مراحـل بـالا بـراى تمـام ذرههـا، سـرعت و موقعيت هر ذره بكروز شله /ست مراحل بالا تا برقرارى شرط توقف تكرار شلده اند.

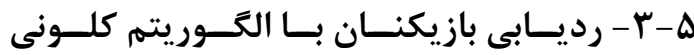

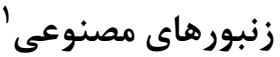

الكوريتم كلونى زنبورهاى مصنوعى يك الكوريتم بهينهسازى است كه از رفتار زنبورهاى عسل براى جستجوى

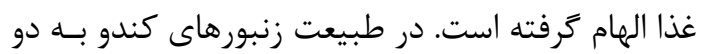

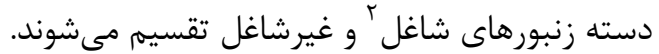

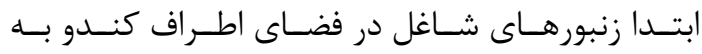
جستجوى غذا مى بردازند.

${ }^{1}$ Artificial bee colony

${ }^{2}$ Employed 


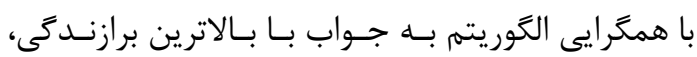
مسير نهايى حركت بازيكنها و داور مشخص شده است.

\section{9- بيادهسازى و ارزيابى نتايج}

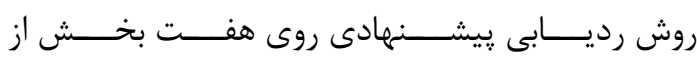

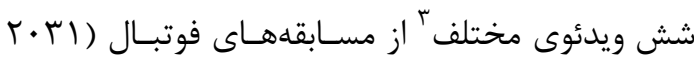

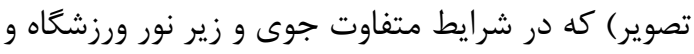

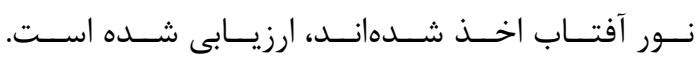

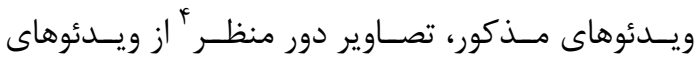

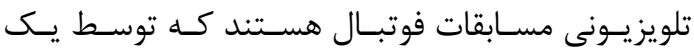

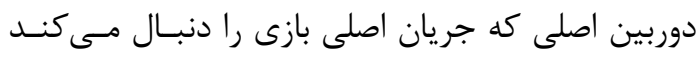

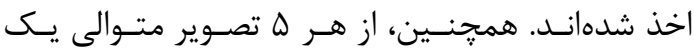

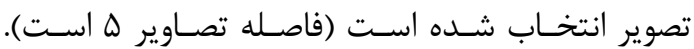
اندازه تصاوير اين ويدئوها نيز XVAV $V \cdot F \times \Delta V G \quad \Delta F Y X \Delta V G \quad V Y \cdot X \Delta V G \quad V Y \cdot X \Delta V G$

مستــير بازيكنـــان در دو فضـــاى تصـــوير و مــــل استخراج شدهانـد و روى موزايـكـ تصـويرى حاصـل از داز

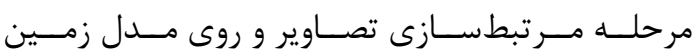
ايجاد شده بر اساس اسـتانداردهاى فيفـا (انـدازه مــدل

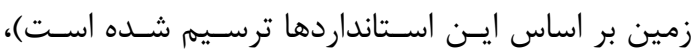

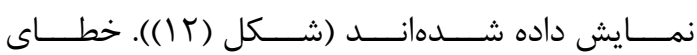

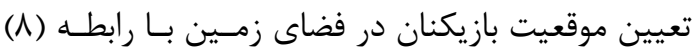

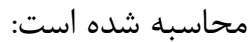

$R M S E=\sqrt{\frac{1}{N} \sum_{i=1}^{N}\left(\Delta X_{i}^{2}+\Delta Y_{i}^{2}\right)}$

رابطه) (^) S, كه بهترتيب ميزان انحراف موقعيت بازيكن

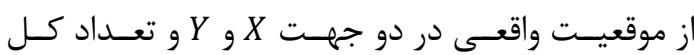
بازيكنان هستند. خطـاى تعيـين موقعيـت بازيكنـان در

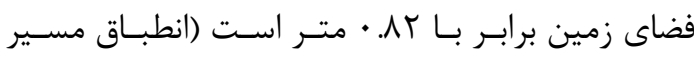

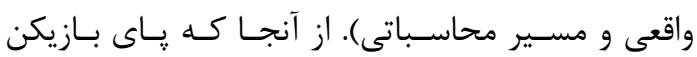

\footnotetext{
${ }^{3}$ Beira-Mar versus Benfica, a short clip, Yemen versus Kuwait, Ayaks versus Real, La Gantoise versus FC Malines, Lyon versus Bayern

${ }^{4}$ Far view frames
}

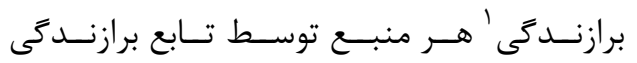

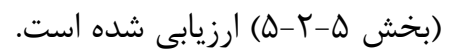

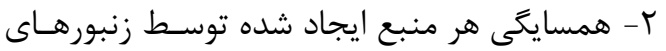

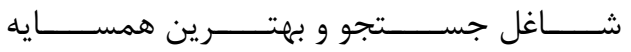

$$
\text { (بالاترين برازندگى) انتخاب شده است. }
$$

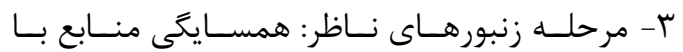

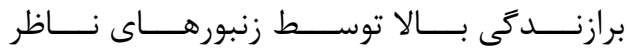

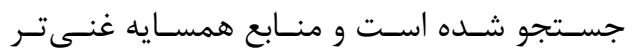
جايكزين منبع اوليه شدهاند. بهمنظور جسـتجوى

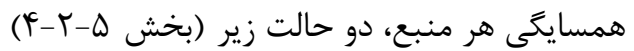

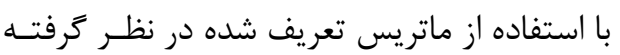
شده است: الف) حالت تعويض ؛ّ فرزندهـاى دو بـازيكن در صـورت اشتراك تعويض شدهاند و همسايكى هاى جستجو شـده نـان

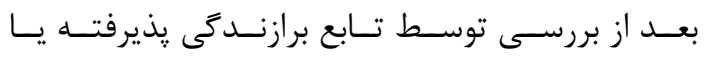
رد شدهاند. ب) تغيير يك يال: با توجه به مجموع عناصر هر سـتون

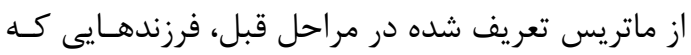

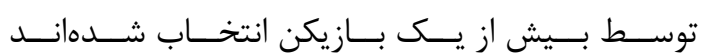

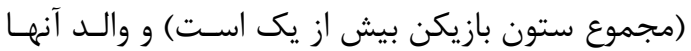

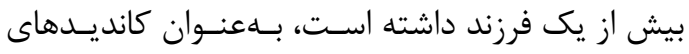

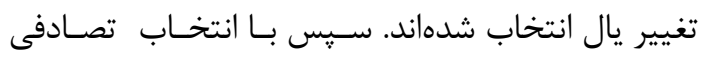
يكى از كانديدها، فرزند ديخرى بهعنوان ادامه مسير والد بازيكن در نظر گرفته شده است.

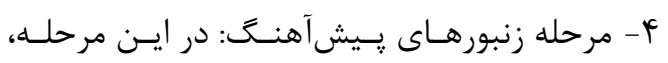

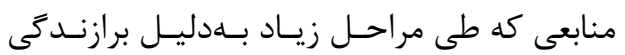

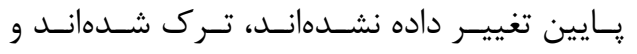

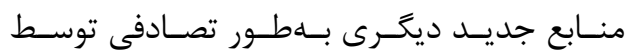

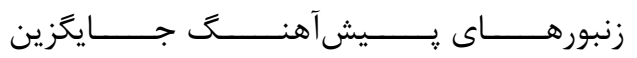
منابع ترك شده گرديدهاند.

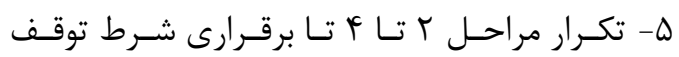
(بيشينه تعداد تكرارها)

${ }^{1}$ Fitness

${ }^{2}$ Switch 
ششان داده شده است.

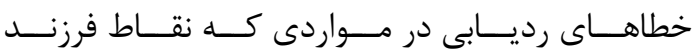

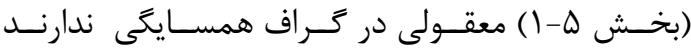
(نويز، تشخيصهاى اشتباه، دو تكه شدن بـدن بـازيكن در مرحله آشكارسازى يا وقتى بازيكن از محسـدوده ديـــ

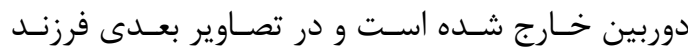
نداشته است) ايجاد شدهانـد. در شـكل (سا) يـك لبـهـ

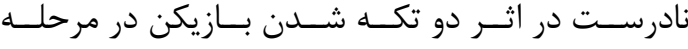
آشكارسازى و ايجاد نويز (بيضى صورتى) و عـدم وجـود فرزند محتملتر، شكل گرفته است. همجنــين بـه دليـل

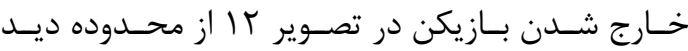

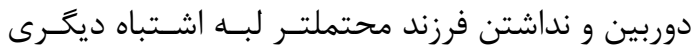

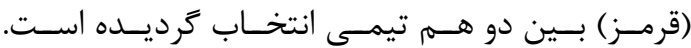

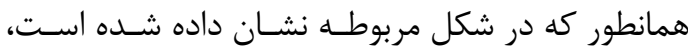
تشخيص اينكه موقعيت كا در واقع بـهـ كـداميك از دو بازيكن در تصوير | | اختصاص دارد كار سادهاى نيست.

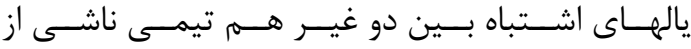

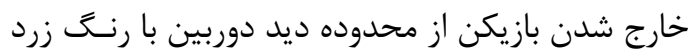

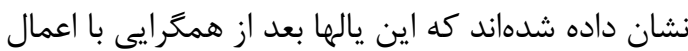

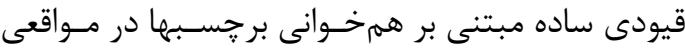
كه بازيكن دو والد دارد قابل اصلاحند. همجنين خطاى تهن

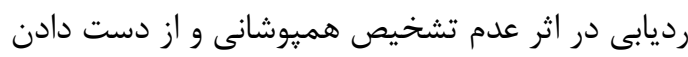

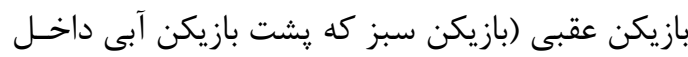

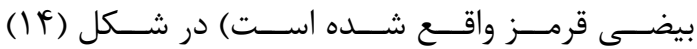
نشان داده شده است. هر جند موقعيت بازيكن عقبى بـــه

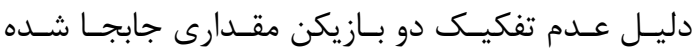
(موقعيت بازيكن سبز داخل بيضى قرمز به سمت يايين

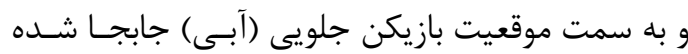

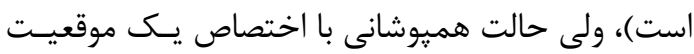
به دو بازيكن مشخص شده است. همجنــين مســيرهاى بازيكنها بـه دليـل انتخــاب محتملتـرين مســير، در اثـر

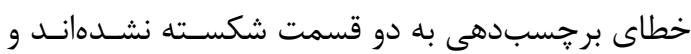

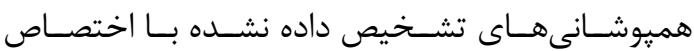

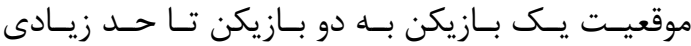

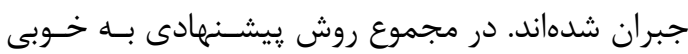

موقع دويدن تا يكى متر هم باز مىشـود و هــر نقطـهاى

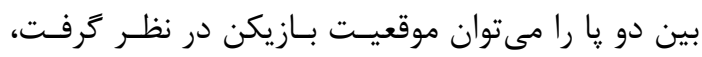
اين مقدار خطا قابل قبول است.

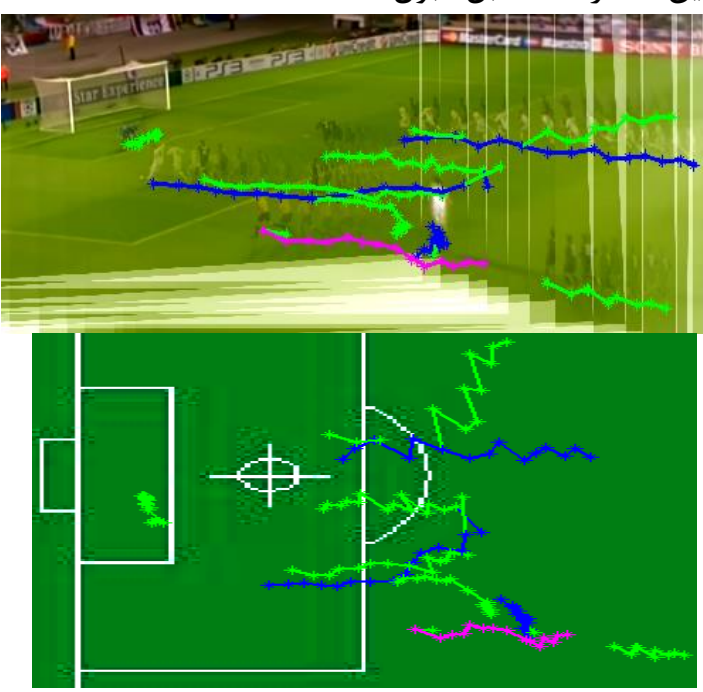

شكل rا: نتايج رديابى در فضاى تصوير و مدل (آبى: بازيكنان تيم ا، سبز: بازيكنان تيم ז، صورتى دودي داور ) روش رديابى با روابط زير ارزيابى شده است و دو معيـار

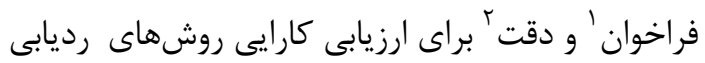

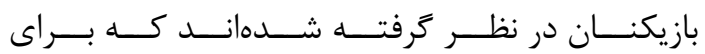
يك روش مناسب بايد هر دو معيار بالا باشند. ) رابطه (9) فراخوان $=\frac{T P}{T P+F N}$ = $=\frac{T P}{T P+F P}$ نمونه مثبت بازيكن است و نمونه منفى هر جيـزى غيـر از بازيكن (تكه جمن، خط و غيره) است. در روابـط بـالا

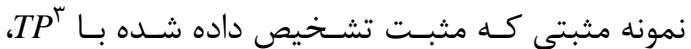

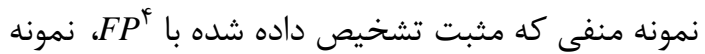

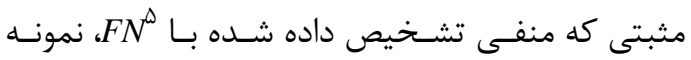

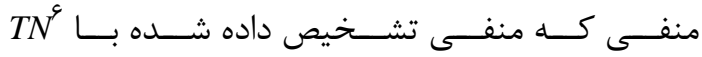

\footnotetext{
${ }^{1}$ Recall

${ }^{2}$ Precision

${ }^{3}$ True positive

${ }^{4}$ False positive

${ }^{5}$ False negative

${ }^{6}$ True negative
} 


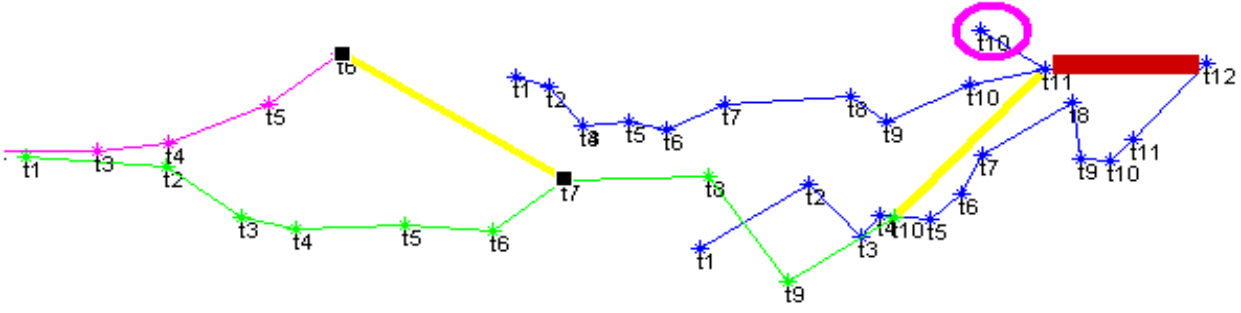

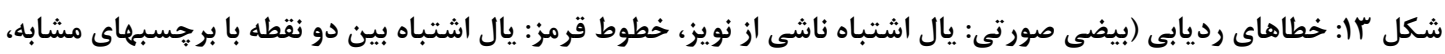

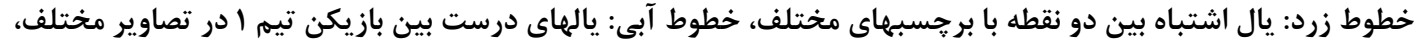

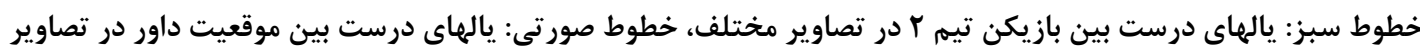

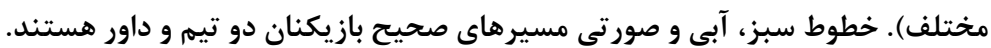

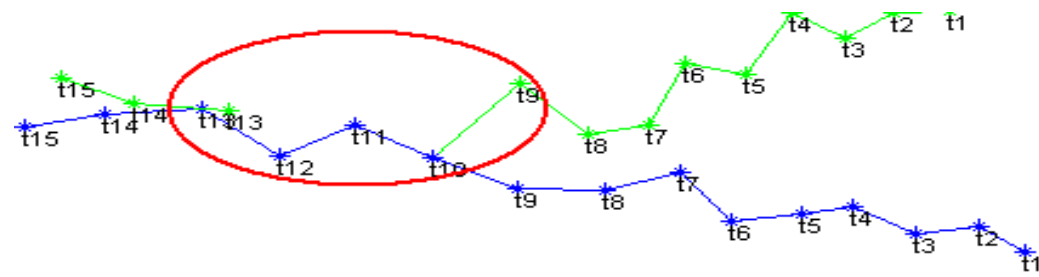

شكل fl: خطاى رديابى در اثر عدم تشخيص هميوشانى و از دست دادن بازيكن عقبى (بازيكن سبز كه يشت بازيكن آبى داخل بيضى قرمز واقع شده است)

بررسى نشده است يا روشها با معيارهاى متفاوت مـثنلا توانايى روش در حل مشكل هميوشانى ارزيابى شدهانـــ

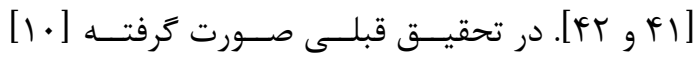

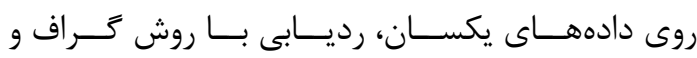

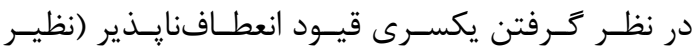

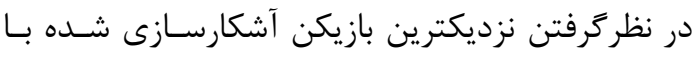

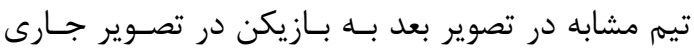

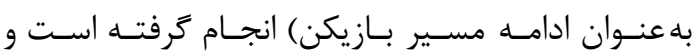

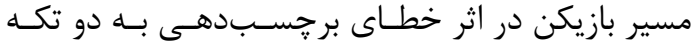

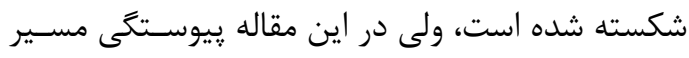

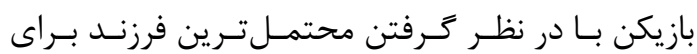

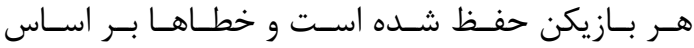
تعداد يالهاى اشتباه ارزيابى شدهاند. در كـل بازيكنـان

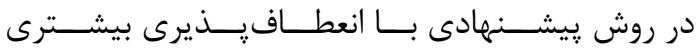

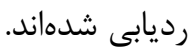

ميـانگين نتــايج رديــابى بازيكنــان در جــدول (1) نشان داده شده است و با روش جسـتجوى كوتـاهتـرين مسير مقايسه شـده اسـت. لازم بـهـ ذكـر اسـت كـهـ بـا افزايش تعداد كانديـدها (لبـهـهـا)، تعـداد دورهـاى لازم براى همكر ايى الكَوريتم افزايش يافته اسـت. همجِنــين،

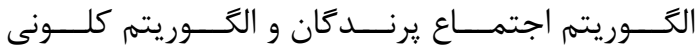
زنبورهاى مصنوعى در بعضى ويدئوها در دام كمينههاى محلى كرفتار شده است كه اين مشكل با افزايش تعـداد اوليه يرندهها تا حدى حل شده است. لازم به ذكر است

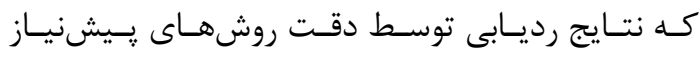

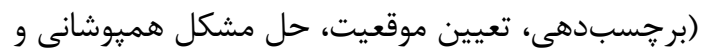

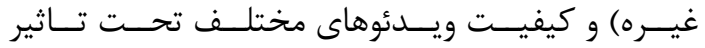

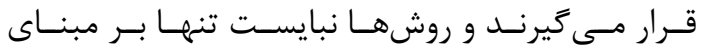

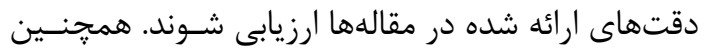
در بعضى مقالهها مشكل همبوشانى همزمان بـا رديـابى دانى

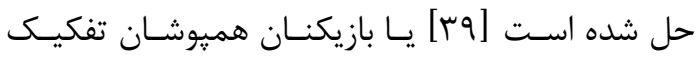

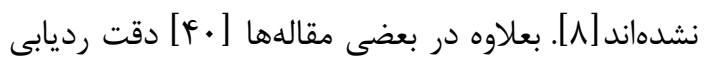


انتخاب مىشـوند. اخـر تعـداد خطــوط مــدل 1 أباشـد،

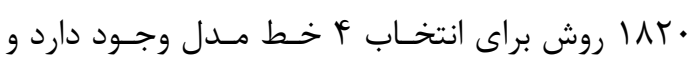
تعداد كانديدهاى تناظريابى خطوط تصوير و مدل برابـر

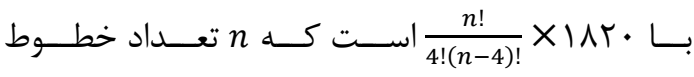

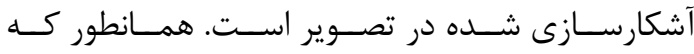
مشاهده مىشود، تعـداد كانديـدهاى تناظريـابى بسـيار

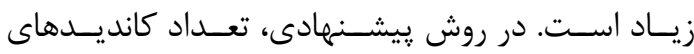

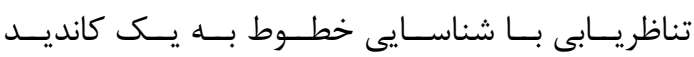
كاهش يافته است.

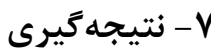

در ايـن تحقيـق، يـسـ از اسـتخراج موقعيـت بازيكنــان

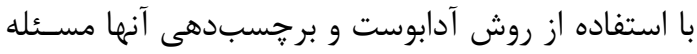

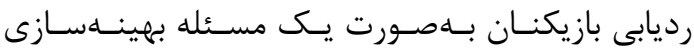

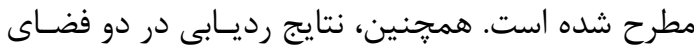

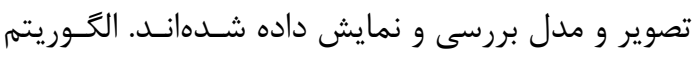
كلونى زنبورهاى مصنوعى و الكوريتهم اجتماع يرندگان با

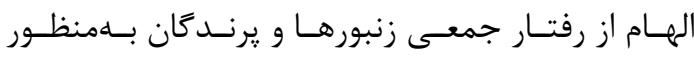

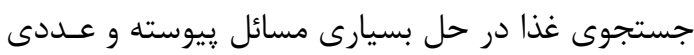
بهصورت كارا استفاده شده است و در مــواردى بــه حــل

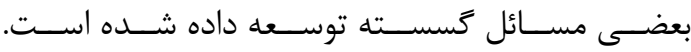
بهلطور خلاصه، حل مســله گَسسـته رديـابى بازيكنـان

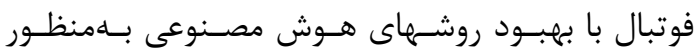

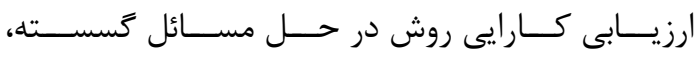

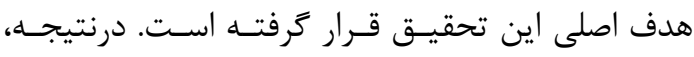

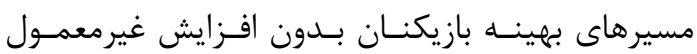

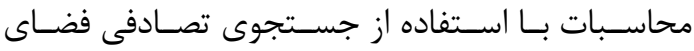
جوابها استخراج شدهاند. همجٍنين بهدليـل زيـاد بـودن

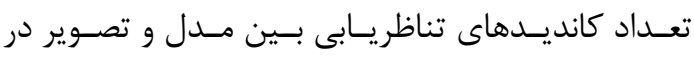

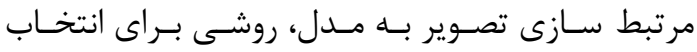

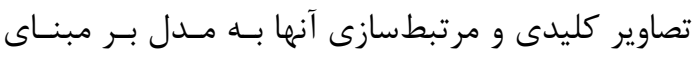

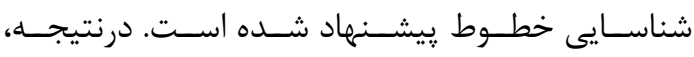
تعداد كانديدهاى تناظريابى به ميزان قابل توجه كاهش

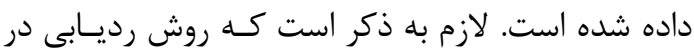

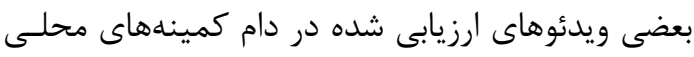

\begin{tabular}{|c|c|c|}
\hline روش & فراخوان & دقت \\
\hline الكوريتم اجتماع يرندكان & $q p, t$ & $91, r$ \\
\hline 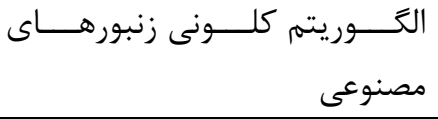 & 94,1 & 94 \\
\hline روش جستجوى كوتاهترين مسير & $\Lambda \mathrm{V}$ & NF \\
\hline
\end{tabular}

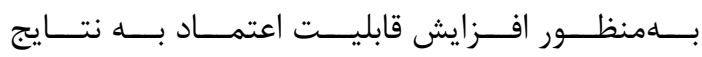

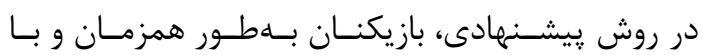

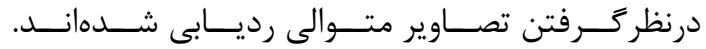
رديابى همزمان بازيكنان مستلزم جستجوى تعداد زيـاد

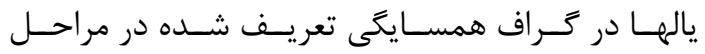
قبل است. بنـابراين، فضـاى جسـتجو بــه دليـل وجـود

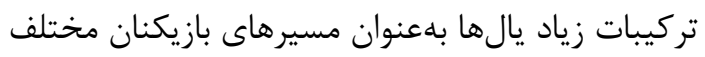
فضايى بزرى است. اخر معيار ارزيابى حجـم محاسـبات تعداد دفعات محاسبه تابع برازندگى در نظر گرفته شود، تعداد دفعات محاسـبه تـابع برازنـدگى از ضـرب تعـداد

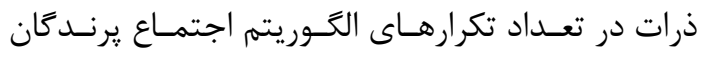
محاسبه مىشود. درحاليكه تعداد دفعات محاسـبه تـابع

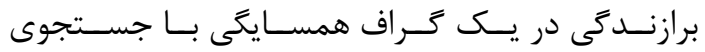

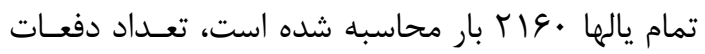

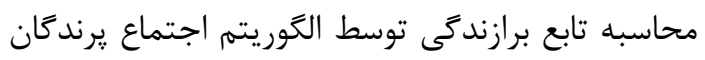
• ل بار محاسبه شده است. در نتيجه، ميزان محاسـبات

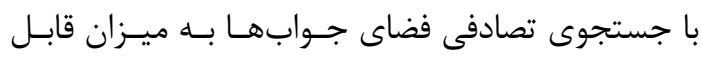

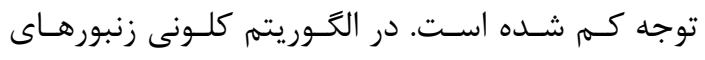

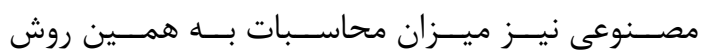
كاهش جشمخًير داشته است. دستاورد مهمم ديخر اين تحقيق كاهش فضـاى جسـتجو در مرتبطسازى مدل و تصوير است. همـانطور كـه قـبلا شرح داده شد، ارتبـاط بـين تصـوير و مـدل بـا انتقــال يروزكتيو دوبعدى و با حداقل f خط متناظر در تصـوير و مدل محاسبه مى شــود. بـراى ايـن منظــور، تركيبـات

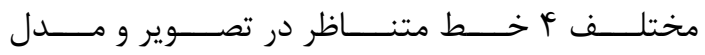
ارزيابى مىشوند و f خط متناظر كه بهتـرين ارتبـاط را

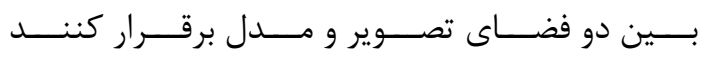




$$
\text { بازيكنان مطالعه خواهند شد. }
$$

[1] T. D’Orazio, M. Leo, “A review of visionbased systems for soccer video analysis, Pattern Recognition", Vol. 43, No. 8, pp. 2911-2926, 2011.

[2] P. Oskouie, S. Alipour, A. M. EftekhariMoghadam, "Multimodal feature extraction and fusion for semantic mining of soccer video: a survey", Artificial Intelligence Review, Vol. 42, No. 2, pp. 173-210, 2014.

[3] J. Ren, et al, "Multi-camera video surveillance for real-time analysis and reconstruction of soccer games," Journal of Machine Vision and Applications, Vol. 21, No. 6, pp. 855-863, 2010.

[4] A. Dearden, et al, "Tracking football player movement from a single moving camera," 3rd European Conference on Visual Media Production, London, UK, pp. 29-37, 2006.

[5] Pascual J. Figueroa, et al, “Tracking soccer players aiming their kinematical motion analysis," Computer Vision and Image Understanding, Vol. 101, No. 2, pp. 122135, February 2006.

[6] T.S. Chiang, et al, “An improved mean shift algorithm based tracking system for soccer game analysis", Proceedings of 2009 APSIPA Annual Summit and Conference, Sapporo, Japan, pp. 4-7, 2009.

[7] N. Vandenbroucke, et al, "Contribution of a color classification to soccer players tracking with snakes," IEEE International Conference on Systems, Man, and Cybernetics. Computational Cybernetics and Simulation, Vol. 4, pp. 3660-3665, 12-15 Oct 1997.

[8] S. H. Khatoonabadi, M. Rahmati, "Automatic soccer players tracking in goal scenes by camera motion elimination," Image and Vision Computing, Vol. 27, No. 4, pp. 469-479, 3 March 2009.

[9] S. W. Joo, R. Chellappa, "A multiple-

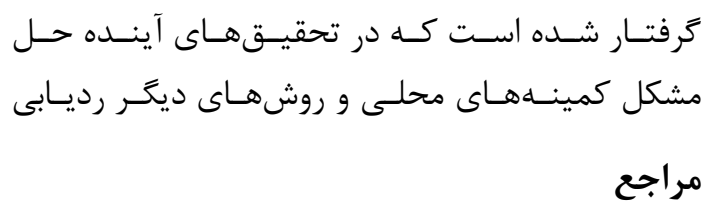

hypothesis approach for multiobject visual tracking," IEEE Transactions on Image Processing, Vol. 16, No. 11, pp. 2849-2854, Nov. 2007.

[10] M. Manafifard, et al, "Player localization and tracking in field model space using graph representation in football broadcast videos", A Joint Publication of the Iranian Society of Instrument and Control Engineers and the K.N. Toosi University of Technology, Vol. 5, No. 1, pp. 77-86, 2011.

[11] J. Berclaz, et al, "Multiple object tracking using k-shortest paths optimization", IEEE Transactions on Pattern Analysis and Machine Intelligence (TPAMI), Vol. 33, No. 9, pp. 1806-1819, 2011.

[12]H. B. Shitrit, J. Berclaz, F. Fleuret and P. Fua, "Tracking multiple people under global appearance constraints", IEEE International Conference on Computer Vision, November 2011.

[13]A. Yilmaz, et al, "Object tracking: A survey”, ACM Comput. Surv, Vol. 38, pp. 1-44, December 2006.

[14] J. Liu et al, "Automatic player detection, labeling and tracking in broadcast soccer video", Pattern Recognition, Vol. 30,No. 2, pp. 103-113, 2009.

[15] G. Liu, et al, "A novel approach for tracking high speed skaters in sports using a panning camera", Pattern recognition, Vol. 42, No. 11, pp. 2922-2935, 2009.

[16] J. Kennedy, et al, "Particle swarm optimization", In: Proceedings of IEEE international conference on neural networks, Perth, Australia, pp. 1942-1948, 1995.

[17] J. Kennedy, R.C. Eberhart, "Discrete binary version of the particle swarm algorithm", In: Proceedings of the IEEE International Conference on Systems, Man and Cybernetics, Vol. 5, pp. 4104-4108, 
Orlando, Florida, USA, 1997.

[18] W. Cheng, et al, "Solving traveling salesman problems with time windows by genetic particle swarm optimization", In Proc. IEEE Congress on Evolutionary Computation, pp. 1752-1755, Hong Kong, 2008.

[19]L. Fang, et al, "Particle swarm optimization with simulated annealing for TSP", In Proceedings of the 6th Conference on 6th WSEAS Int. Conf. on Artificial Intelligence, Knowledge Engineering and Data Bases, Vol. 6, pp. 206-210, Corfu Island, Greece, 2007.

[20]K.P. Wang, et al, "Particle swarm optimization for traveling salesman problem", International Conference on Machine Learning and Cybernetics, Vol. 3, pp. 1583-1585, 2003.

[21]H. Fan, "Discrete Particle Swarm Optimization for TSP based on Neighborhood", Journal of Computational Information Systems, Vol. 10, pp. 34073414, 2010.

[22]D. Karaboga, "An idea based on honey bee swarm for numerical optimization", Technical Report TR06. Computer Engineering Department, Engineering Faculty, Erciyes University, 2005.

[23] L. P. Wong, et al, “An efficient bee colony optimization algorithm for traveling salesman problem using frequency-based pruning," In Proceedings of the 7th IEEE International Conference on Industrial Informatics (INDIN09), Cardiff, UK, pp. 775-782, 2009.

[24]D.T. Pham, et al, "The bees algorithm - a novel tool for complex optimization problems", Proceedings of IPROMS 2006 Conference, pp. 454-461, 2006.

[25] S. Hemamalini, et al, "Economic load dispatch with valve-point effect using artificial bee colony algorithm", 32th National Systems Conference, India, pp. 1719, 2008.

[26] M. Shokouhifar, et al., "An artificial bee colony optimization for MRI fuzzy segmentation of brain tissue", In Proceedings of the 2011 International Conference on Management and Artificial Intelligence, Vol. 6, Bali, Indonesia, pp. 610, 2011.

[27] M. D. Rossetti, et al, "Application of multiobjective bee colony optimization algorithm to automated red teaming", In Proceedings of the 41th Winter Simulation Conference, Austin, TX, pp. 1798-1808, 2009.

[28]I. Brajevic, et al, "Performance of the improved artificial bee colony algorithm on standard engineering constrained problems", International journal of mathematics and computers in simulation, Vol. 5, No. 2, pp. 135-143, 2011.

[29] A. L. Bolaji, et al, "Artificial bee colony algorithm for curriculum-based course timetabling problem", In: ICIT 2011 the 5th International Conference on Information Technology, Malaysia, Jordan, 2011.

[30]C. S. Chonget al, "A bee colony optimization algorithm to job shop scheduling", In Proc. of the 2006 Winter Simulation Conference, Monterey, CA, pp. 1954-1961, 2006.

[31] S. J. Mason, et al, "Bee colony optimization algorithm with big valley landscape exploitation for job shop scheduling problems", In Proceedings of the 2008 Winter Simulation Conference, Austin, TX, pp. 2050-2058, 2008.

[32] Y. Liu, et al, "A new method to calculate the camera focusing area and player position on playfield in soccer video", Visual Communications and Image Processing, Vol. 5960, pp. 1523-1533, 2005.

[33] Bruce D. Lucas, Takeo Kanade, “An iterative image registration technique with an application to stereo vision", International Joint Conference on Artificial Intelligence, pp. 674-679, 1981.

[34] C. Tomasi, Takeo Kanade, "Detection and tracking of point features", Carnegie Mellon University Technical Report CMU-CS-91132, April 1991. 


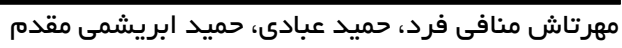

[35]Y. Xie, Q. Ji, “A new efficient ellipse detection method", Proceedings of 16th International Conference on Pattern Recognition, Vol.2, pp. 957-960, 2002.

[36]C. A. Basca, M. Talos and R. Brad, "Randomized hough transform for ellipse detection with result clustering", International Conference on "Computer as a Tool", Belgrade, pp. 1397-1400, 2005.

[37]L. Barceló, et al, "Robust methods and representations for soccer player tracking and collision resolution", In Proceedings of the 4th International Conference on Image and Video Retrieval, Vol. 3568, pp. 237 246, Singapore, 2005.

[38] M. Manafifard, et al, "Multi-player detection in soccer broadcast videos using a blobguided particle swarm optimization method," Multimedia Tools and Applications, pp. 1-30, 2016.

[39]P. Figueroa, et al, "Tracking soccer players using the graph representation", In Proceedings of the 17th International Conference on Pattern Recognition (ICPR), Vol. 4, pp. 787-790, Washington, DC, USA, 2004.

[40]Beetz, M., et al, "Visually tracking football games based on TV broadcasts", IJCAI 2007, Proceedings of the 20th International Joint Conference on Artificial Intelligence, pp. 1805-1819, Hyderabad, India, 2007.

[41]K. Sato, J. K. Aggarwal, "Tracking soccer players using broadcast TV images", In IEEE International Conference on Advanced Video and Signal Based Surveillance (AVSS), pp. 546 - 551, 2005.

[42] P.J. Figueroa et al, "Tracking Soccer Players aiming their Kinematical Motion Analysis", Computer Vision and Image Understanding, Vol. 101, No. 2, pp. 122-135, 2006. 


\title{
Player Tracking using Graph and Artificial Intelligence methods in Soccer Broadcast Videos
}

Mehrtash Manafifard ${ }^{1}$, Hamid Ebadi ${ }^{2}$, Hamid Abrishami Moghaddam ${ }^{3}$

1- Ph.d student of Photogrammetry and Remote Semsing in Department of Geomatics, College of Engineering, K.N. Toosi University of Technology

2- Assisstant professor in Department of Geomatics, College of Engineering, K. N. Toosi University of Technology

3- Assisstant professor in Department of Electrical Engineering, College of Engineering, K. N. Toosi University of Technology

\begin{abstract}
Player tracking in soccer broadcast videos can be further processed by coaches and experts to judge weaknesses and strengths of the players and the team. Following player detection by Adaboost, player labeling, occlusion handling and player localization, player trajectory is extracted using combination of graph with artificial bee colony (ABC) and particle swarm optimization (PSO) in this research. PSO and ABC are optimization method inspired by the flocking behavior of birds and bees which were originally customized for continuous function value optimization. However, the need for modifying the discrete version in different applications is inevitable. In this paper, a modified version of discrete PSO and ABC for player tracking is proposed. Moreover, a new method for registering frames to the field model based on line recognition is proposed to diminish the search space. Finally, the proposed algorithm is tested on seven shots from six different soccer broadcast videos. Experimental results show the capability of the proposed method for extracting player trajectory in soccer broadcast videos.
\end{abstract}

Key words: Tracking, Football, Gragh, Artificial bee colony, Particle swarm optimization.

Correspondence Address: Dept. of Photogrammetry and Remote Semsing - K.N. Toosi University of Technology - Valieasr Street - Tehran - Iran

Tel: +9888770218

Email: mmanafifard@mail.kntu.ac.ir 